\title{
Precipitation susceptibility in marine stratocumulus and shallow cumulus from airborne measurements
}

\author{
Eunsil Jung $^{1, \text { a }}$, Bruce A. Albrecht ${ }^{1}$, Armin Sorooshian ${ }^{2,3}$, Paquita Zuidema ${ }^{1}$, and Haflidi H. Jonsson ${ }^{4}$ \\ ${ }^{1}$ Department of Atmospheric Sciences, University of Miami, Miami, FL, 33149, USA \\ ${ }^{2}$ Department of Chemical and Environmental Engineering, University of Arizona, Tucson, AZ, 85721, USA \\ ${ }^{3}$ Department of Hydrology and Atmospheric Sciences, University of Arizona, Tucson, AZ, 85721, USA \\ ${ }^{4}$ Naval Postgraduate School, Monterey, CA, 93943, USA \\ ${ }^{a}$ now at: National Institute of Meteorological Sciences, Jeju, 63568, South Korea
}

Correspondence to: Eunsil Jung (eunsil.jung@gmail.com)

Received: 22 February 2016 - Published in Atmos. Chem. Phys. Discuss.: 14 March 2016

Revised: 27 August 2016 - Accepted: 30 August 2016 - Published: 14 September 2016

\begin{abstract}
Precipitation tends to decrease as aerosol concentration increases in warm marine boundary layer clouds at fixed liquid water path (LWP). The quantitative nature of this relationship is captured using the precipitation susceptibility $\left(S_{o}\right)$ metric. Previously published works disagree on the qualitative behavior of $S_{o}$ in marine low clouds: $S_{o}$ decreases monotonically with increasing LWP or cloud depth $(H)$ in stratocumulus clouds $(\mathrm{Sc})$, while it increases and then decreases in shallow cumulus clouds $(\mathrm{Cu})$. This study uses airborne measurements from four field campaigns on $\mathrm{Cu}$ and Sc with similar instrument packages and flight maneuvers to examine if and why $S_{o}$ behavior varies as a function of cloud type. The findings show that $S_{o}$ increases with $H$ and then decreases in both $\mathrm{Sc}$ and $\mathrm{Cu}$. Possible reasons for why these results differ from those in previous studies of Sc are discussed.
\end{abstract}

\section{Introduction}

Cloud-aerosol interactions are considered to be one of the most important forcing mechanisms in the climate system (IPCC, 2013). It is believed that aerosols suppress precipitation in warm boundary layer clouds. However, there is considerable disagreement on the magnitude and even on the sign of how aerosol perturbations affect cloud fraction and lifetime (Stevens and Feingold, 2009). Furthermore, aerosol effects on clouds and precipitation are not readily separable from the effects of meteorology. The precipitation suscepti- bility metric, $S_{o}$, quantifies how aerosol perturbations alter the magnitude of the precipitation rate $(R)$ while minimizing the effects of macrophysical factors (i.e., meteorology) (Feingold and Siebert, 2009). It is defined as

$S_{o}=-\frac{\mathrm{d} \ln R}{\mathrm{~d} \ln N_{\mathrm{d}}}$,

and is evaluated at fixed cloud macrophysical properties, such as cloud thickness $(H)$ or liquid water path (LWP). In Eq. (1), aerosol effects are embedded in the cloud droplet number concentration $\left(N_{\mathrm{d}}\right)$ variable since aerosols serve as cloud condensation nuclei (e.g., as aerosol concentration increases, $N_{\mathrm{d}}$ increases). The minus sign is used in Eq. (1) to achieve a positive value of $S_{o}$ due to the expectation that increasing aerosols reduce precipitation (all else being fixed). Towards improving the representation of precipitation in larger-scale models, the application of Eq. (1) has also been studied using more highly resolved models and remote sensing (e.g., Feingold and Siebert, 2009; Sorooshian et al., 2009; Terai et al., 2015; Hill et al., 2015). In the original work on $S_{o}$ (Feingold and Siebert, 2009), cloud-base $R$ and $N_{\mathrm{d}}$ were used. Since then, slightly different definitions of $S_{o}$ have been applied. For example, Sorooshian et al. (2009) used an aerosol proxy (e.g., Aerosol Optical Depth and Aerosol Index) instead of $N_{\mathrm{d}}$ for their satellite data analysis. Terai et al. $(2012,2015)$ further defined precipitation susceptibility as the sum of the susceptibilities of drizzle intensity $\left(S_{\mathrm{I}}\right)$ and drizzle fraction $\left(S_{\mathrm{f}}\right), S_{R}=S_{\mathrm{I}}+S_{\mathrm{f}}$, where $S_{\mathrm{I}}$ is equivalent to $S_{o}$. The difference between $S_{\mathrm{I}}$ and $S_{o}$ is how large a threshold of precipitation is applied for calculating 
$S_{o}$ or $S_{\mathrm{I}}$. Other studies focus on the probability of precipitation (POP), defined as the ratio of the number of precipitating events over the total number of cloudy events. $S_{\text {pop }}$ is used in some studies of precipitation susceptibility (e.g., Wang et al., 2012; Mann et al., 2014; Terai et al., 2015), and is equivalent to the $S_{\mathrm{f}}$ used within Terai et al. (2012). In addition to the different definitions of precipitation susceptibility, various forms of $R$ and $N_{\mathrm{d}}$ (e.g., cloud-base, vertically integrated, or ground-based values) with different data thresholds have been used for the calculation of the precipitation susceptibility depending on the data available. In this study, precipitation susceptibility indicates $S_{o}$ as defined in Eq. (1) unless otherwise stated.

In global climate models (GCMs), aerosol effects on rain rate are represented by either a prognostic scheme or an empirical diagnostic scheme. When GCMs consider aerosols, the rain rate $R$ is often parameterized in terms of LWP and $N_{\mathrm{d}}$ as Eq. (2)

$R=\operatorname{LWP}^{\alpha} N_{\mathrm{d}}^{-\beta}$.

Climate models typically assume a fixed value of the autoconversion parameter ( $\beta$ in Eq. 2 ), ranging between approximately 0 and 2 (e.g., Rasch and Kristjansson, 1998; Khairoutdinov and Kogan, 2000; Jones et al., 2001; Rotstayn and Liu, 2005; Takemura et al., 2005). Readers should note that rain rates from liquid clouds are usually from two terms; one is from autoconversion and the other is from accretion (see Sect. 3.3). Since $S_{o}$ in Eq. (1) includes contributions from both autoconversion and accretion, in the case where accretion has little contribution to rain rate, $S_{o}$ may then be equivalent to the exponent $\beta$ in Eq. (2) at fixed LWP. Field studies of precipitating stratocumulus $(\mathrm{Sc})$ clouds have reported $\beta$ values ranging from 0.8 to 1.75 at fixed LWP (e.g., Pawlowska and Brenguier, 2003; Comstock et al., 2004; vanZanten et al., 2005; Lu et al., 2009). Such single power-law fits, however, do not capture the changes in $S_{o}$ with LWP or $H$, which is important since previous works have revealed that the response of cloud rain rates to aerosol perturbations vary as a function of LWP (or $H$ ).

The qualitative behavior of $S_{o}$ has been studied for low clouds using models, remote sensing data, and in situ measurements. For model studies of warm cumulus clouds (e.g., the adiabatic parcel model of Feingold and Siebert, 2009), $S_{o}$ varies from 0.5 to 1.1 with increasing LWP, and exhibits three regimes. At low LWP, not enough water is available with which to initiate rain, and $S_{o}$ is insensitive to aerosol perturbations. At intermediate LWP, suppression of collisioncoalescence by the increased aerosols is most effective. We will refer to this regime as the ascending branch of $S_{o}$ following Feingold et al. (2013). At high LWP, the precipitation rate is more strongly influenced by the LWP, and $S_{o}$ decreases with increasing LWP (the descending branch of $S_{o}$ ). This LWP-dependent pattern of $S_{o}$ is supported by satellite observations (Sorooshian et al., 2009, 2010) and large-eddy simulations (LESs) (Jiang et al., 2010) for warm trade cumulus clouds. In contrast, Terai et al. (2012) showed that $S_{R}$ monotonically decreased with increasing LWP and $H$ in Sc clouds based on in situ measurements acquired during the VAMOS Ocean-Cloud-Atmosphere-Land Study Regional Experiment (VOCALS-REx) field study, while their $S_{\mathrm{I}}$, similar to $S_{o}$ in aforementioned studies, did not reveal any significant change with $H$ and maintained a value of $\sim 0.6$. These inconsistent results have raised questions of how cloud type impacts behavior of $S_{o}$ as a function of either $H$ or LWP.

To begin to unravel why differences in the various studies exist, Feingold et al. (2013) showed in modeling studies that the time available for collision-coalescence $\left(t_{\mathrm{c}}\right)$ is critical for determining the LWP-dependent behavior of $S_{o}$, and may be at least partly responsible for some of the differences. Gettelman et al. (2013) also showed how the microphysical process rates impact $S_{o}$ in the NCAR Community Atmosphere Model version 5 (CAM5) GCM. They showed that the behavior of $S_{o}$ with LWP differs between the GCM and the steady-state model of Wood et al. (2009); the values of $S_{o}$ were constant or decreased with LWP in the steady state model (consistent with Terai et al., 2012; Mann et al., 2014), whereas the GCM $S_{o}$ behavior was more consistent with Feingold and Siebert (2009), Sorooshian et al. (2009, 2010), Jiang et al. (2010), Feingold et al. (2013), and Hill et al. (2015). In their study, altered microphysical process rates were able to significantly change the magnitudes of $S_{o}$, but the qualitative behavior of $S_{o}$ with LWP remained unchanged (i.e., $S_{o}$ increases with LWP, peaks at an intermediate LWP, then decreases with LWP). More recently, Mann et al. (2014) analyzed 28 days of data from the Azores Atmospheric Radiation Measurement (ARM) mobile facility where the prevalent type of clouds are cumulus (20\%), cumulus under stratocumulus (10-30\%), and single-layer stratocumulus ( $10 \%)$. They showed that $S_{\text {pop }}$ slightly decreased with LWP. Terai et al. (2015) estimated precipitation susceptibility $\left(S_{\mathrm{I}}+S_{\mathrm{pop}}\right)$ in low-level marine stratiform clouds, which included stratus and stratocumulus clouds, using satellite data. The values of $S_{o}$ in their study generally showed similar behavior to that reported by Mann et al. (2014). Hill et al. (2015) examined how the representation of cloud microphysics in climate model contributes to the behavior of $S_{o}$. They found that single-moment schemes produce the largest uncertainty in $S_{o}$. Only through increasing the number of prognostic moments (i.e., multi-moment schemes capable of prognosing the rain droplet number as well as mass) could the dependence of $S_{o}$ on a particular scheme be reduced.

The inconsistent behavior of $S_{o}$ in previous studies for warm boundary layer clouds motivates the current study. The focus of this paper is to examine and compare the qualitative behavior of $S_{o}$ in $\mathrm{Cu}$ and $\mathrm{Sc}$ using similar airborne measurements encompassing four field campaigns. Two were focused on Sc clouds (VOCALS-REx and the Eastern Pacific Emitted Aerosol Cloud Experiment, Sect. 2.2) and two campaigns targeted $\mathrm{Cu}$ clouds (Barbados and Key West Aerosol Cloud Experiments, Sect. 2.3). The strength of these four 
field campaigns' airborne measurements is that the same research aircraft was deployed with a similar flight strategy and instrument packages, facilitating a comparative analysis. Each of the four field experiments sampled an area of about $100 \times 100 \mathrm{~km}$, and thus, the mean interrelationships examined are representative of the GCM spatial resolution. Data and methods are discussed in Sect. 2, followed by results and discussion in Sects. 3 and 4, respectively. The findings are summarized in Sect. 5. Acronyms used in this study are listed in Table A1 of the Appendix.

\section{Data and methods}

\subsection{TO aircraft}

The Center for Interdisciplinary Remotely Piloted Aircraft Studies (CIRPAS) Twin Otter (TO) research aircraft served as the principal platform from which observations for these four experiments were made. During these four deployments, the TO supported similar instrument packages, and performed similar cloud sampling maneuvers, including vertical soundings and level-leg flights below, inside, and above the clouds. Each research flight lasted $\sim 3-4 \mathrm{~h}$. The TO included the following three in situ probes for characterizing aerosol, cloud, and precipitation size distributions: the Passive Cavity Aerosol Spectrometer Probe (PCASP), Cloud Aerosol Spectrometer (CAS), and Cloud Imaging Probe (CIP), with each resolving particles of diameters $0.1-2.5 \mu \mathrm{m}, 0.6-60 \mu \mathrm{m}$, and $25-1550 \mu \mathrm{m}$, respectively. A zenith-pointing $95 \mathrm{GHz}$ Doppler radar was mounted on top of the aircraft and detected cloud and precipitation structures above the aircraft. Detailed information of the instruments on the TO and flight strategies is provided elsewhere (Zheng et al., 2011; Jung, 2012). All the instruments were operational during the flights analyzed in this study except for the cloud radar, which was not operational during the VOCALS TO flights.

$S_{o}$ is calculated from Eq. (1) within bins of the cloud thickness $H$. $H$ was estimated as the height difference between cloud tops and bases. Cloud tops were determined by the cloud radar with a time resolution of $3 \mathrm{~Hz}$ and vertical resolution of $24 \mathrm{~m}(5 \mathrm{~m})$ in height for $\mathrm{Cu}(\mathrm{Sc})$. Cloud bases of $\mathrm{Cu}$ were determined by the lifting condensation level (LCL) calculated from the average thermodynamic properties of the sub-cloud layer for a given day. The LCLs varied little for $\mathrm{Cu}$, for example, during the Barbados Aerosol Cloud Experiment (Sect. 2.3); the LCLs were $653.9 \pm 146 \mathrm{~m}$ on average from the aircraft measurements, which agreed with the 2-year LCL climatology in this region $(700 \pm 150 \mathrm{~m})$ as documented in Nuijens et al. (2014). Although it is not shown in this study, $S_{o}$ was also estimated by using the cloud-base heights determined from the $\mathrm{Cu}$ cloud-base level-leg flights; these results were similar to those shown in this study.

In stratocumulus clouds, cloud tops are well defined due to the strong capping temperature inversion (see Zheng et al., 2011) and cloud bases vary more than tops (e.g., Fig. 2 of Bretherton et al., 2010). As a result, the way that the cloud base is determined may affect $S_{o}$ since the changes in cloud base alternatively can change the cloud thickness. Therefore, we estimate $S_{o}$ using three different definitions for cloud base. The first method is with LCLs calculated from the average thermodynamic properties of the sub-cloud layer (shown as cb-lcl in Fig. 4, same as $\mathrm{Cu}$ ). For the second and third definitions (cb-local and cb-mean), cloud bases are determined from the lowest heights where the vertical gradients of liquid water contents (LWCs) are the greatest from the LWC profiles. The LWC profiles are obtained (i) when the aircraft enters the cloud decks to conduct level legs (cb-local), and (ii) from the nearest one or two soundings to the cloudbase level-leg flights. The average height of these two lowest heights (cb-mean, the average of $\mathrm{i}$ and ii) is used in this study, along with cb-lcl and cb-local (Fig. 4 later). In general, the heights approximately corresponded to the lowest heights that the LWCs exceeded by $0.01 \mathrm{~g} \mathrm{~m}^{-3}$. $S_{o}$ was also estimated by using the heights from the cloud-base level-leg flights as the cloud bases as was done for $\mathrm{Cu}$, and the qualitative behavior of $S_{o}$ was preserved (not shown).

$N_{\mathrm{d}}$ and $R$ were calculated from the drop size distribution (DSD), which is obtained from CAS (forward scattering) and CIP probes during the cloud-base level-leg flights, respectively. The CAS probe acquires data every $10 \mathrm{~Hz}$ and then the DSDs at each channel are averaged to $1 \mathrm{~Hz}$. The CIP acquires data every $1 \mathrm{~s}$. The cloud radar samples at $3 \mathrm{~Hz}$ and then is averaged to $1 \mathrm{~Hz}$ to match the probe data. Therefore, $N_{\mathrm{d}}, R$, and $H$ in Eq. (1) were calculated in $1 \mathrm{~s}$ resolution (except for VOCALS-REx; see Sect. 2.4). The impact of using $1 \mathrm{~s}$ data on the $S_{o}$ estimates will be discussed later in Sect. 3.2. $R$ is defined as

$R=\frac{\pi}{6} \int_{25 \mu \mathrm{m}}^{1550 \mu \mathrm{m}} N(D) D^{3} u(D) \mathrm{d} D$,

where $u(D)$ is the fall speed of a drop with diameter $D$. Three fall speed formulations are used: (1) $u=k_{1} r^{2}$ with $k_{1} \approx 1.19 \times 10^{6} \mathrm{~cm}^{-1} \mathrm{~s}^{-1}$ was used for cloud droplets up to $30 \mu \mathrm{m}$ radius; (2) $u=k_{3} r$ with $k_{3} \approx 8 \times 10^{3} \mathrm{~s}^{-1}$ was used for the size range of $40 \mu \mathrm{m}<r<0.6 \mathrm{~mm}$; and (3) $u=k_{2} r^{1 / 2}$ with $k_{2} \approx 2.01 \times 10^{3} \mathrm{~cm}^{1 / 2} \mathrm{~s}^{-1}$ for droplets of $0.6 \mathrm{~mm}<r<$ $2 \mathrm{~mm}$.

\subsection{Stratocumulus cloud field campaigns: VOCALS-REX and E-PEACE}

From October to November 2008, the VOCALS-REx took place over the southeast Pacific $\left(69-86^{\circ} \mathrm{W}, 12-31^{\circ} \mathrm{S}\right)$, an area extending from the near coastal region of northern Chile and southern Peru to the remote ocean (Zheng et al., 2011; Wood et al., 2011; also see Fig. 1). Three aircraft were deployed during VOCALS from 14 October to 15 November 


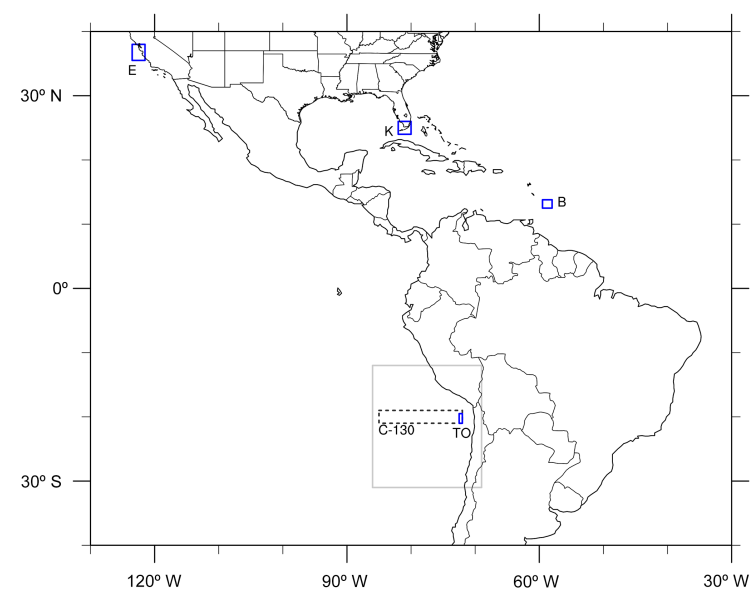

Figure 1. The geographical location of each field campaign (blue solid). E indicates E-PEACE, K indicates KWACEX, and B shows BACEX. The entire domain of VOCALS-REx is displayed as a solid grey box with domains of C-130 (dashed grey) and TO (solid blue) flights.

(NSF/NCAR C-130, DOE G-1, CIRPAS TO). The TO sampled more coastal marine stratocumulus decks near $20^{\circ} \mathrm{S}$, $72^{\circ} \mathrm{W}$ (Fig. 1) than the other two planes. Readers should note that the data in Terai et al. (2012) used for their $S_{R}$ calculations, were also obtained from VOCALS. However, their results were based on NSF/NCAR C-130 flights that sampled cloud decks away from the coastal area (Fig. 1). Wood et al. (2011) provided a comprehensive description of VOCALS experiments and Zheng et al. (2011) provided a description of TO aircraft data during the VOCALS. TO data from flights with decoupled boundary layers, abnormally higher cloud bases, and moist layers above cloud tops were excluded, reducing the total number of flights analyzed to 13 from the original total of 18 (Table 1).

From July to August 2011, the Eastern Pacific Emitted Aerosol Cloud Experiment (E-PEACE) took place off the coast of Monterey, California, to better understand the response of marine stratocumulus to aerosol perturbations (Russell et al., 2013). E-PEACE included sampling controlled releases of (i) smoke from the deck of the research vessel Point Sur, and (ii) salt aerosol from the TO research aircraft, along with sampling (iii) exhaust from container ships transiting across the study area (see Fig. 2 from Russell et al., 2013). During 9 out of 30 E-PEACE flights, salt powder (diameter of 1-10 $\mu \mathrm{m}$ ) was directly introduced into the cloud decks to examine the effects of giant cloud condensation nuclei (GCCN) on the initiation of warm precipitation (Jung et al., 2015). After excluding the seeding cases and the non-typical Sc decks, 13 flights remained from which we analyzed data (Table 1). Detailed information about E-PEACE and TO data can be found elsewhere (Russell et al., 2013; Wonaschütz et al., 2013).

\subsection{Marine cumulus cloud field campaigns: BACEX and KWACEX}

Shallow marine cumulus clouds are by far the most frequently observed cloud type over the Earth's oceans, yet remain poorly understood, and have not been investigated as extensively as oceanic stratocumulus. The marine environments in the Caribbean Sea and the Atlantic Ocean provide an excellent area to sample shallow marine cumulus clouds with a high propensity to precipitate. In addition, African dust is transported westward off of Africa periodically over the North Atlantic, affecting clouds in its path including around Barbados and Key West, and thus providing an excellent opportunity to observe aerosol-cloud-precipitation interactions. To better understand such interactions in these trade cumuli regimes, the Barbados Aerosol Cloud Experiment (BACEX) was carried out off the Caribbean island of Barbados during mid-March and mid-April 2010 (Jung et al., 2013), and the Key West Aerosol Cloud Experiment (KWACEX) during May 2012 near Key West (Fig. 1). For the BACEX, we analyzed 12 flights (Table 1). Readers are referred to Jung et al. (2016) for detailed information about the cloud and aerosol properties during the BACEX. The marine atmosphere during KWACEX was dry overall. A total of 6 out of 21 flights sampled shallow marine cumulus clouds, of which 4 had sufficient data for analysis (Table 1).

\section{$2.4 S_{o}$ calculation details}

The distribution of $N_{\mathrm{d}}$ and $R$, with the corresponding $H$, is shown in Fig. 2 for each field campaign as scatter diagrams of $N_{\mathrm{d}}$ and $R$. All data shown in Fig. 2 were obtained during the cloud-base level-leg flights. The southeast Pacific (SEP) Sc decks (VOCALS, Fig. 2a) were overall drier and more polluted than those in the northeast Pacific (NEP) Sc decks (E-PEACE, Fig. 2c); $R=0.03 \mathrm{~mm} \mathrm{day}^{-1}$ (median) and $N_{\mathrm{d}}=232 \mathrm{~cm}^{-3}$ in VOCALS, but $R=1.04 \mathrm{~mm} \mathrm{day}^{-1}$ and $N_{\mathrm{d}}=133 \mathrm{~cm}^{-3}$ in E-PEACE. During E-PEACE, high $N_{\mathrm{d}}$ was observed in a few cases, (e.g., $N_{\mathrm{d}}>400 \mathrm{~cm}^{-3}$ in Fig. 2c), and they were likely associated with the emitted aerosols from the ship exhaust and smoke (Russell et al., 2013; Wang et al., 2014; Sorooshian et al., 2015). The marine environments of the Caribbean Sea showed wide variations of $R$ (e.g., order of $10^{-2}$ to $10^{2} \mathrm{~mm} \mathrm{day}^{-1}$; Fig. $2 \mathrm{~b}$ and d). The Barbados campaign sampled the most pristine environment of the four campaigns $\left(N_{\mathrm{d}}<350 \mathrm{~cm}^{-3}, N_{\mathrm{d}}=61 \mathrm{~cm}^{-3}\right.$ on average), reflecting the isolated location of the island in the North Atlantic even though the experiment period included the most intense dust events of 2010 (Jung et al., 2013). The marine environment near Key West was more polluted than Barbados throughout the KWACEX campaign (Fig. $2 \mathrm{~d}, N_{\mathrm{d}}=206 \mathrm{~cm}^{-3}$ on average).

$S_{o}$ was about 0.62 for E-PEACE (linear regression correlation coefficient $r=0.34$ ), if calculated using all the individual $1 \mathrm{~Hz}$ data points shown in Fig. 2 where $H$ ranges from 

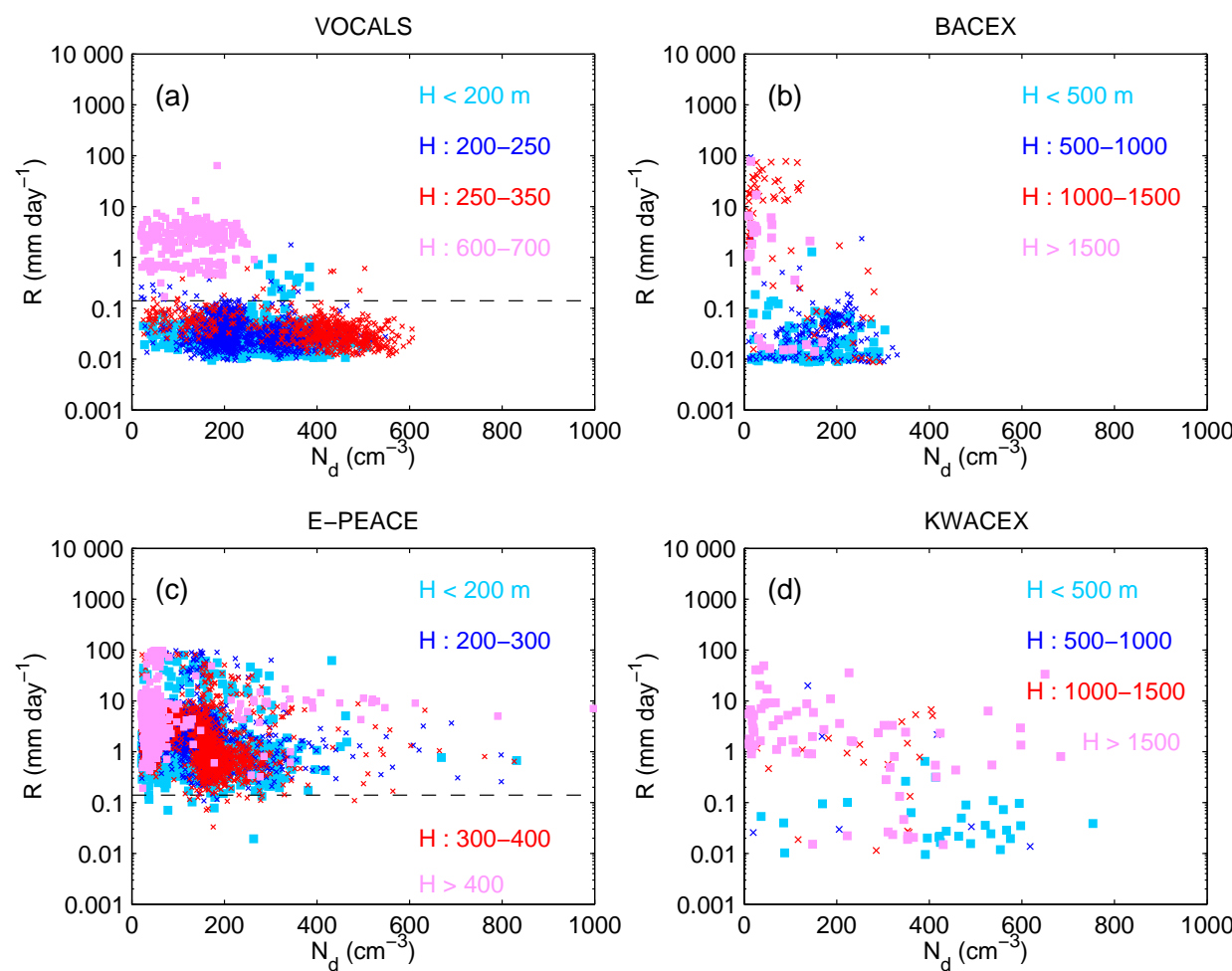

Figure 2. Scatter diagrams of cloud droplet number concentrations, $N_{\mathrm{d}}$, and precipitation, $R$, for four field campaigns. Colors indicate cloud thickness $H$. The dashed line indicates an $R$ value of $0.14 \mathrm{~mm} \mathrm{~d}^{-1}$.

$\sim 100 \mathrm{~m}$ to $500 \mathrm{~m}$. However, $S_{o}$ was about $0.42(r=0.21)$ if one rainy day (shown as double circles in Fig. 10 later) was excluded from the analysis, suggesting the artifact of wet scavenging (see Sect. 4), a different predominant cloud microphysical process (autoconversion vs. accretion) or the influence of macrophysical properties other than $H$. These E-PEACE $S_{o}$ values agree with values estimated in previous campaigns in the same NEP region for $H \sim 200-600 \mathrm{~m}: S_{o}$ $\sim 0.46-0.48$ using $H$, and $S_{o} \sim 0.60-0.63$ using LWP (Lu et al., 2009). $S_{o}$ during VOCALS is about $1.07(r=0.46)$ for $H \sim 150-700 \mathrm{~m}$. Overall, $S_{o}$ values in this study are within the range of $S_{o}$ from the previous field studies of precipitating stratocumulus clouds $\left(S_{o} \sim 0.8\right.$ to 1.75 for a fixed LWP in the studies of Pawlowska and Brenguier, 2003; Comstock et al., 2004; vanZanten et al., 2005). Values of $S_{o}$ for BACEX and KWACEX are about $0.89(r=0.38)$ and $0.77(r=0.39)$, respectively.

Although single power-law fits for a given field campaign give the general sense of $S_{o}$ values, they do not show the qualitative behavior of $S_{o}$ with $H$, which reveals which thickness is most susceptible to aerosol perturbations. To further examine this, $S_{o}$ is calculated by assigning $R$ and $N_{\mathrm{d}}$ into the given intervals of cloud thickness for each campaign. The width of each $H$ interval is taken to be $30 \mathrm{~m}$ for Sc and $50 \mathrm{~m}$ for $\mathrm{Cu}$. The $H$ intervals are arbitrary, but chosen to contain a similar number of data points within each interval and provide a robust $S_{o}$ regardless of the interval choice. Within each

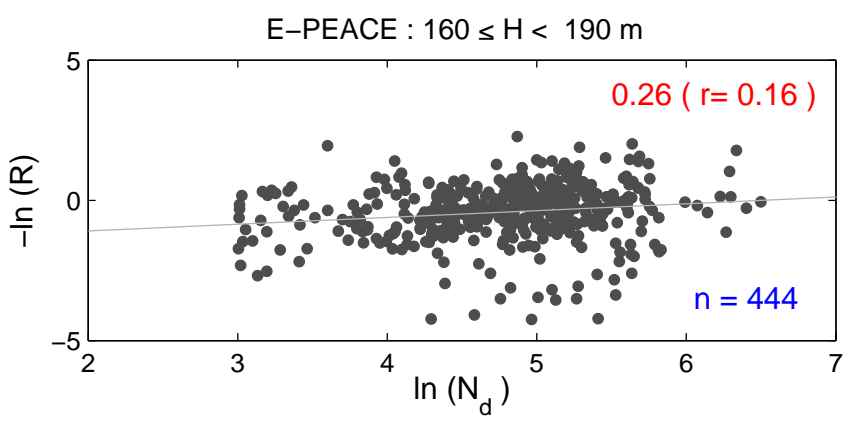

Figure 3. Examples of scatterplots used to calculate precipitation susceptibility $S_{O}$ (i.e., the slope) for E-PEACE. Black dots indicate data points for an $H$ interval between 160 and $190 \mathrm{~m}$. Numbers on the bottom right (blue) indicate the total number of data used. $S_{O}$ and linear coefficient $(r)$ values are shown in the upper right corner. Precipitation, $R$, increases downward in $y$ ordinate, and $N_{\mathrm{d}}$ increases toward the right direction in $x$ abscissa.

$H$ interval, we performed a linear regression to find a best fit for the natural $\log$ of the precipitation rate against natural $\log$ of $N_{\mathrm{d}}$, and the $S_{o}$ is the slope of the fit (see Figs. 3 and 6 , for example). Cloud data are included in the analysis if the given precipitation rate is greater than a threshold of $0.001 \mathrm{~mm} \mathrm{day}^{-1}$. The low $R$ threshold is chosen to include precipitating and very lightly precipitating clouds. The $0.001 \mathrm{~mm} \mathrm{day}^{-1}$ threshold is indeed very low; the uncer- 
Table 1. Dates (in $\mathrm{mm} / \mathrm{dd}$ format) used for this analysis during each experiment.

\begin{tabular}{|c|c|c|c|c|}
\hline No. & VOCALS (Sc) & E-PEACE (Sc) & $\operatorname{BACEX}(\mathrm{Cu})$ & $\operatorname{KWACEX}(\mathrm{Cu})$ \\
\hline Period & Oct-Nov 2008 & Jul-Aug 2011 & Mar-Apr 2010 & May 2012 \\
\hline \multirow[t]{2}{*}{ Location } & Southeast Pacific & Northeast Pacific & Barbados (Caribbean Sea & Key West \\
\hline & Sc decks & Sc decks (California coast) & and North Atlantic) & (Caribbean Sea) \\
\hline RF1 & $10 / 16(2), 232[29,3]$ & $7 / 19[236,2]$ & $3 / 22[39,25]$ & $5 / 22$ (1st flight) \\
\hline RF2 & $10 / 18(3), 292 \pm 22[152,2]$ & $7 / 21[669,144]$ & $3 / 23[92,4]$ & $5 / 22$ (2nd flight) \\
\hline RF3 & $10 / 19$ (3) $323 \pm 16[402,28]$ & $7 / 22[610,39]$ & $3 / 24[69,1]$ & $5 / 23$ \\
\hline RF4 & $10 / 21(1), 172[376,2]$ & $7 / 23[369,20]$ & $3 / 25[68,8]$ & $5 / 24$ \\
\hline RF5 & $10 / 22(2), 224[364, N A]$ & $7 / 26[258,131]$ & $3 / 26[28,1]$ & - \\
\hline RF6 & $10 / 26(2), 208[395,11]$ & $7 / 27[702,7]$ & $3 / 29[103, \mathrm{NA}]$ & - \\
\hline RF7 & $10 / 27(1), 142 \pm 38[336,2]$ & $7 / 29[731,17]$ & $3 / 30[526, \mathrm{NA}]$ & - \\
\hline RF8 & $10 / 30(2), 213[311,170]$ & $8 / 2[395,1]$ & $3 / 31[184,2]$ & - \\
\hline RF9 & $11 / 1(4), 641[146,8]$ & $8 / 3[629,1]$ & $4 / 5[138,4]$ & - \\
\hline RF10 & $11 / 9(1), 164 \pm 18[392,44]$ & $8 / 4[378,19]$ & $4 / 7[171,7]$ & - \\
\hline RF11 & $11 / 10(1), 194 \pm 21[279,1]$ & $8 / 5[364,93]$ & $4 / 10[133,43]$ & - \\
\hline RF12 & $11 / 12(2), 249[409,66]$ & $8 / 10[721,1]$ & $4 / 11[123,5]$ & - \\
\hline RF13 & $11 / 13(1), 183[174,35]$ & $8 / 11[10,4]$ & - & - \\
\hline
\end{tabular}

RF indicates the research flight. However, note that RFs from E-PEACE and VOCALS are not the same as RFs from Russell et al. (2013) and Zheng et al. (2011), respectively. The daily mean cloud thickness (mean $\pm 1 \sigma$ ) for VOCALS is shown with the $H$ category (the group number is shown in the parenthesis). See the details in Sect. 2.4. Numbers inside brackets indicate $e$-folding time (seconds) of $N_{\mathrm{d}}$ and $R$. NA $=$ not available

tainty in rain rate calculation is larger than $0.001 \mathrm{~mm} \mathrm{day}^{-1}$ threshold. For all intents and purposes, the $0.001 \mathrm{~mm} \mathrm{day}^{-1}$ threshold is equivalent to no precipitation. The impacts of the $R$ threshold and $H$ intervals on the $S_{o}$ estimates are discussed in Appendices B and C, respectively. An example of $S_{o}$ is shown in Fig. 3 from E-PEACE using every $1 \mathrm{~s}$ cloud data point (i.e., $N_{\mathrm{d}}$ and $R$ ) for $H$ between 160 and $190 \mathrm{~m}$. The slope (i.e., linear fit) in Fig. 3 corresponds to an $S_{o}$ value of 0.24 . The value of $S_{o}(0.24)$ is then plotted in the corresponding $H$ on the $H-S_{o}$ diagram (e.g., Fig. 4 at the $H$ of $174 \mathrm{~m}$, which corresponds to the average $H$ of the interval). The same procedure is repeated for all $H$ intervals to obtain the complete pattern of $S_{o}$ with $H$. We tested and applied a few criteria in the $S_{o}$ calculations, such as minimum $R$ thresholds, and the total number of cloud data points and spans of $N_{\mathrm{d}}$ for a given $H$ interval. Based on these sensitivity tests, we calculated $S_{o}$ exclusively if $N_{\mathrm{d}}$ varied a sufficient amount (e.g., $\mathrm{d} \ln \left(N_{\mathrm{d}}\right)$ spans at least 2.2) for a given $H$ interval since little variation of $N_{\mathrm{d}}$ does not provide the proper perturbation of aerosols. For example, in Fig. 3 a, $\operatorname{d} \ln \left(N_{\mathrm{d}}\right)$ spans about 3.5. Slightly different and broader criteria were applied for $\mathrm{Cu}$ mainly due to the lower number of data points sampled in $\mathrm{Cu}$. However, the qualitative behavior of $S_{o}$ was robust as long as the variation of $N_{\mathrm{d}}$ was sufficiently large, regardless of the other criteria, although the details were different (e.g., Fig. B1). In Fig. 4, most of the slopes are statistically significant at the $99 \%$ confidence level (e.g., filled symbols). The number of data points used to calculate $S_{o}$ and the linear correlations and the $P$ values indicating the statistically significant level of confidence for the fitted lines are summarized in Table A2 for given $H$ intervals. Additionally, $S_{o}$ is calculated by considering $e$-folding time and by ran-
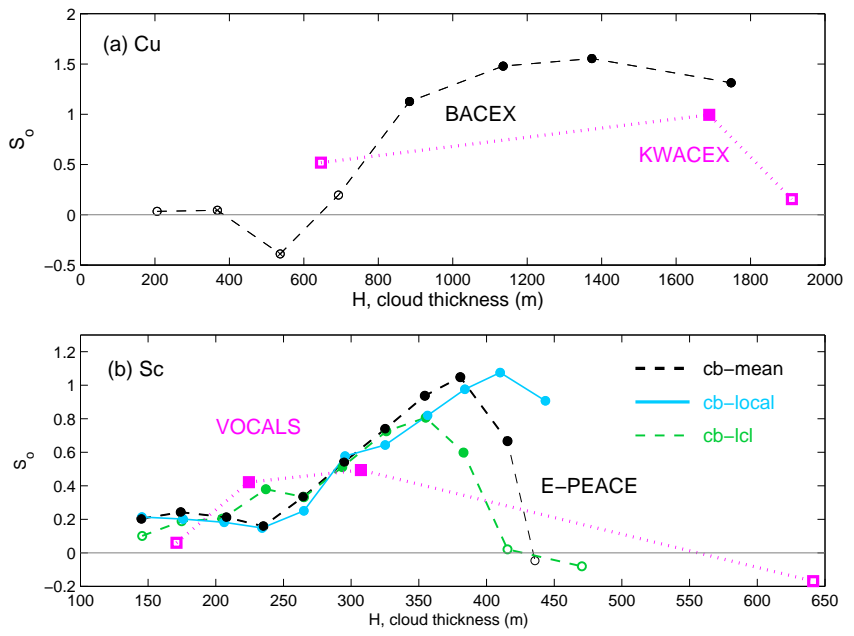

Figure 4. Precipitation susceptibility, $S_{o}$, estimated with aircraft measurements for (a) $\mathrm{Cu}$ (12 flights of BACEX and 4 flights of KWACEX) and (b) Sc (13 flights of E-PEACE and VOCALS-REx). E-PEACE $S_{o}$ is estimated from (i) the cloud-base height, which is identified using LCLs (cb-lcl) and (ii) from the vertical structures of LWCs (lowest height where the vertical gradient of LWC is the greatest) as the aircraft enters the cloud deck to conduct the cloudbase level-leg flight (cb-local), and (iii) from the averaged cloudbase heights from the nearby soundings and cb-local (cb-mean). Filled circles are statistically significant at $99 \%$ confidence level. The number of data points used for $S_{O}$ estimates and their statistical significance are shown in Table A2.

domly resampling the flights (Sect. 3.2), and the results are robust. This will be discussed later. 
$S_{o}$ during VOCALS is calculated in slightly different ways from other experiments since the cloud radar failed. First, $H$ is estimated from the vertical structure of LWC for each day (daily mean $H$ ). Once $H$ is determined for each flight, it is assigned to a certain $H$ bin. For example, $H$ values of 9 November $(164 \pm 18 \mathrm{~m})$ and 10 November $(194 \pm 21 \mathrm{~m})$ are similar and thus assigned to the same $H$ bin (i.e., group 1 in Table 1). VOCALS $H$ is classified into four distinct groups. Once $N_{\mathrm{d}}$ and $R$ are assigned to the corresponding $H, S_{o}$ then is estimated by using all the data points that are assigned to the $H$ group (e.g., Fig. 6b-i, later on).

LWP is commonly used as the macrophysical factor when quantifying Eq. (1). However, in this study, we use $H$ as a macrophysical factor since we aim to compare $S_{o}$ for both $\mathrm{Sc}$ and $\mathrm{Cu}$. $H$ corresponds well to LWP for adiabatic clouds, for which LWP $\sim H^{2}$. The adiabatic assumption, which may be valid in Sc, is not valid in $\mathrm{Cu}$ (Rauber et al., 2007; Jung et al., 2016) to calculate LWP. Moreover, the TO did not carry an instrument that measures LWP directly such as a G-band vapor radiometer (e.g., Zuidema et al., 2012). Consequently, the direct comparison with previous results of $S_{o}$ with LWP (e.g., quantitative) is not possible. We also note that LWC decreases as drizzle rates increase (e.g., see Fig. 8d of Jung et al., 2015). Consequently, clouds that are precipitating (higher $R$ ) may have a LWP that is lower than the adiabatic value, and a cloud with a small $R$ may have a LWP close to the adiabatic value. It should be also noted that the ranges of $H$ (and possibly LWP) differ substantially between $\mathrm{Cu}$ and Sc. For example, $H$ of $\mathrm{Cu}$ in this study can be as high as $1700 \mathrm{~m}$, whereas $H$ of Sc is generally less than $500 \mathrm{~m}$ (e.g., Fig. 4). Additionally, $H$ for clouds that begin to precipitate may differ in $\mathrm{Sc}$ and $\mathrm{Cu}$. Further, the LWP for clouds that precipitate would be sub-adiabatic and would have a smaller value of LWP than the LWP for non-precipitating clouds. Consequently, $S_{o}$ that is calculated from cloud fields with diverse cloud types (e.g., Mann et al., 2014; Terai et al., 2015) may be complicated since LWP is shifted to smaller values for (heavily) precipitating clouds, and the $H$ at precipitation initiation may differ between cloud types. In general, the results are used with caution when comparing with other studies in quantifying $S_{o}$ since the dominating cloud process and the choices applied in how to calculate parameters involved with Eq. (1) can differ widely (e.g., Duong et al., 2011).

\section{Results}

\section{1 $\quad S_{o}$ in $\mathrm{Sc}$ and $\mathrm{Cu}$}

In this section, we show $S_{o}$ calculated in three different ways. First, $S_{o}$ is calculated with $1 \mathrm{~s}$ data (Fig. 4) for BACEX, KWACEX, E-PEACE, and VOCALS. Second, $S_{o}$ is calculated with reduced data points that are averaged over the $e$-folding time of $N_{\mathrm{d}}$. We show the results for BACEX, EPEACE, and VOCALS (Figs. 5 and 6). Lastly, $S_{o}$ is calcu-
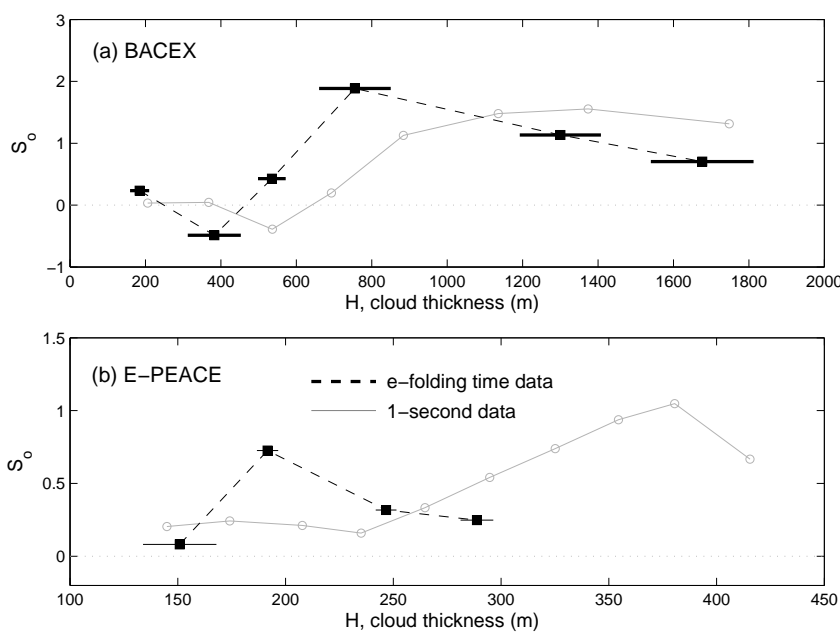

Figure 5. $S_{o}$ estimated with aircraft measurements for (a) BACEX $(\mathrm{Cu})$ and $(\mathrm{b})$ E-PEACE $(\mathrm{Sc})$. The $1 \mathrm{~s}$ data of individual flights are reduced by averaging over the $e$-folding time of $N_{\mathrm{d}}$ for each flight prior to the calculation.

lated with randomly resampled E-PEACE flights (Figs. 8 and 9). We will show the results in turns.

$S_{o}$ as a function of $H$ is shown in Fig. 4 a for Cu. $S_{o}$ is calculated from Eq. (1) with $N_{\mathrm{d}}$ and $R$ that are sampled during the cloud-base level-leg flights at $1 \mathrm{~s}$ resolution. Cloud levelleg flights usually last 7-15 min on average, with an aircraft speed of 50-60 $\mathrm{m} \mathrm{s}^{-1}$. In Fig. 4a, $S_{o}$ during BACEX is insensitive to $H$, fluctuating around zero for clouds shallower than 500-600 m, above which $S_{o}$ begins to increase rapidly with a peak of $\sim 1.6$ near $H \sim 1400 \mathrm{~m}$. After that, $S_{o}$ starts to decrease as $H$ increases. The $S_{o}$ during KWACEX follows $S_{0}$ from BACEX, especially in the thicker cloud regime where the majority of KWACEX data were sampled.

The qualitative behavior of $S_{o}$ for Sc is shown in Fig. 4b. $S_{o}$ during E-PEACE shows $H$-dependent $S_{o}$ patterns that are similar to those from BACEX. In the small $H$ regime $(H<$ $240 \mathrm{~m}), S_{o}$ is almost constant at $\sim 0.2$. For $H>\sim 240 \mathrm{~m}, S_{o}$ increases gradually with increasing $H$ and peaks at $S_{o} \sim 1.0$ near $H \sim 350-400 \mathrm{~m}$. After that, $S_{o}$ decreases with increasing $H$. Figure $4 \mathrm{~b}$ further shows that the overall pattern of $S_{o}$ is similar regardless of how the cloud bases were determined, although the $H$ at which $S_{o}$ peaks changes slightly (cb-mean, cb-local, cb-lcl).

During VOCALS, $S_{o}$ increases with increasing $H$, from $S_{o} \sim 0.1$ near $170 \mathrm{~m}$ to $S_{o} \sim 0.5$ near $300 \mathrm{~m}$. A minimum $S_{o}$ value is shown near $H \sim 640 \mathrm{~m}$. The negative values of $S_{o}$ in the largest $H$ regime possibly result from uncertainties in the $S_{o}$ estimation or in unaccounted-for macrophysical properties such as cloud lifetime. The failure of the cloud radar during VOCALS was responsible for the fewer (four) $H$ groups (Table 1), leading to a low number of $S_{o}$ values. Additionally, no data were available for $H \sim 350-600 \mathrm{~m}$ (Fig. 3). The re- 

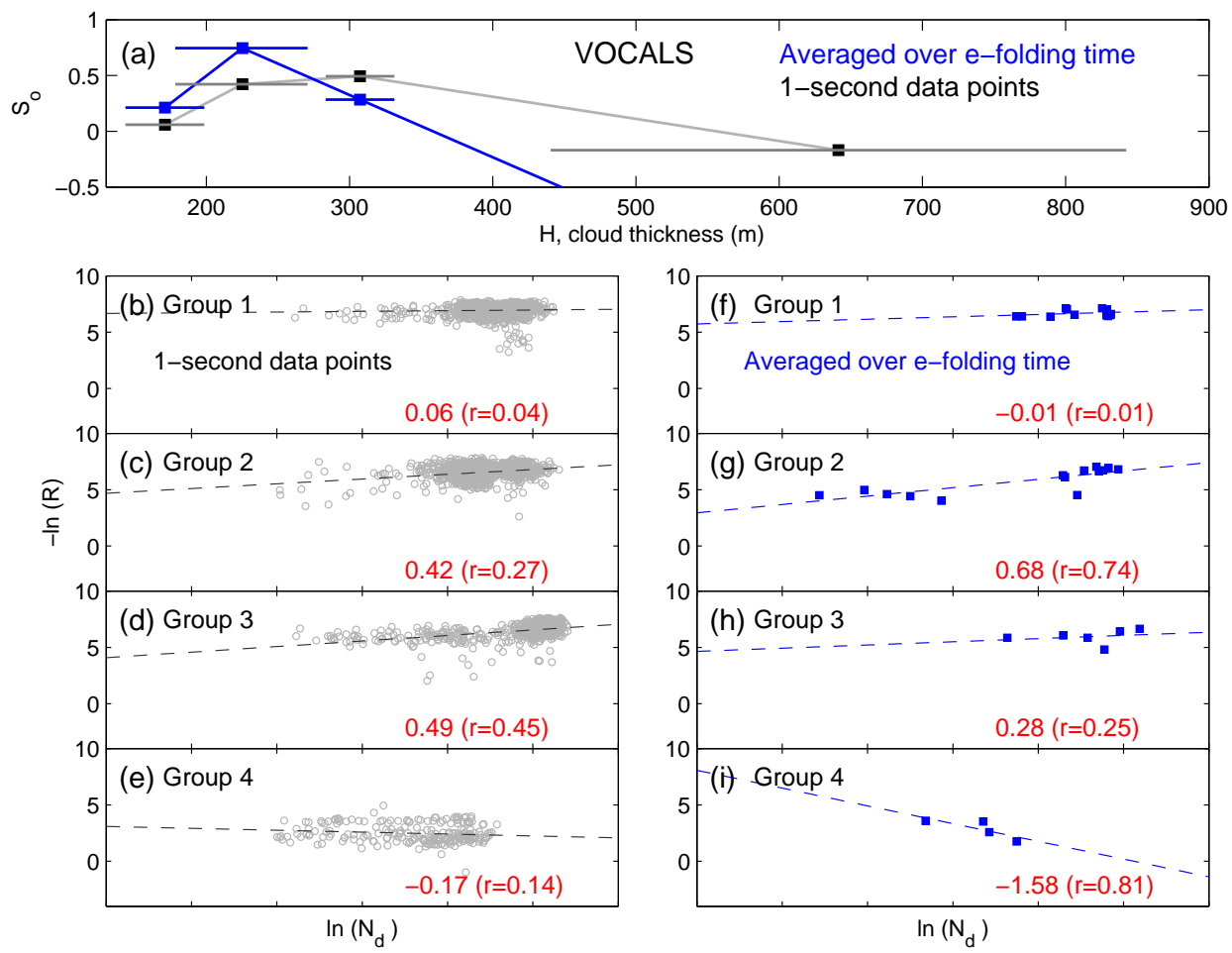

Figure 6. $S_{o}$ for VOCALS TO flight is calculated with $1 \mathrm{~s}$ data (grey) and cloud data that are averaged over an $e$-folding time for each day (blue). The $\ln \left(N_{\mathrm{d}}\right)$ and $-\ln (R)$ diagram is shown for each $H$ interval. The horizontal bar in (a) indicates $\pm 1 \sigma . S_{o}$ is calculated for the cloud data in groups with similar $H$ (shown in Table 1).

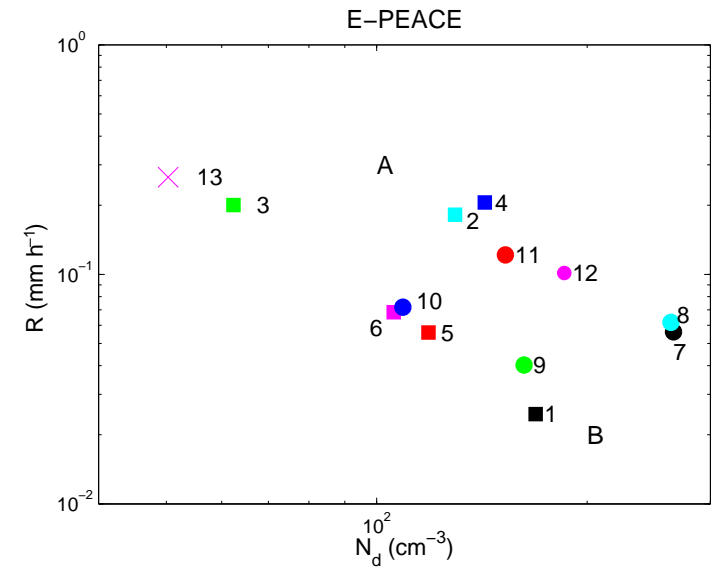

Figure 7. Daily mean values of $N_{\mathrm{d}}$ and $R$ for the 13 E-PEACE flights. Numbers indicate the flight numbers shown in Table 1.

sults of VOCALS clearly show the disadvantage of no cloud radar (i.e., high resolution of LWP or $H$ ) for the $S_{o}$ estimates.

\section{2 $S_{o}$ calculated with an $e$-folding time and randomly resampled flights}

The dependence of $1 \mathrm{~s}$ data $\left(N_{\mathrm{d}}, R\right)$ on each other is tested two ways. First, we calculated $S_{o}$ by considering the $e$ - folding timescale (Leith, 1973) in which an autocorrelation decreases by a factor of $e$. Secondly, we calculated $S_{o}$ by randomly resampling the flights. The $e$-folding time of $N_{\mathrm{d}}$ during E-PEACE was found to vary from 4 to $10 \mathrm{~min}$, while the $e$-folding time of $R$ varied from a few seconds to 1 to $2 \mathrm{~min}$. The $e$-folding time of $N_{\mathrm{d}}$ within the VOCALS TO flights varied from 2 to $6 \mathrm{~min}$, and for the cloud-base precipitation was less than (or approximately) $1 \mathrm{~min}$ (for a horizontal distance of less than $3 \mathrm{~km}$, consistent with Terai et al., 2012). In the case of BACEX $(\mathrm{Cu})$, the overall $e$-folding times were much shorter, varying 1-2 min for $N_{\mathrm{d}}$ and less than $1 \mathrm{~min}$ for $R$. The $e$-folding times of $N_{\mathrm{d}}$ and $R$ are summarized in Table 1 for VOCALS, E-PEACE, and BACEX. KWACEX was not included since there were only four flights.

We calculated $S_{o}$ with data averaged over the upper bounds of the $e$-folding time (i.e., $e$-folding time of $N_{\mathrm{d}}$ ) for E-PEACE, BACEX, and VOCALS flights, and the qualitative behavior of $S_{o}$ reported with $1 \mathrm{~s}$ data is unchanged: $S_{o}$ increases with $H$, then peaks before it decreases again (Fig. 5 for BACEX and E-PEACE and Fig. 6 for VOCALS). However, it should be noted that the $H$ that $S_{o}$ peaks at is shifted toward the lower $H$ consistent with the results of Duong et al. (2011). The shift of $H$ to the lower $H$ is substantial in Sc where the overall $H$ is smaller than $H$ of $\mathrm{Cu}$. Additionally, the effect of the $H$ interval on the $S_{o}$ estimates is discussed in Appendix C. In general, the results are robust regardless 

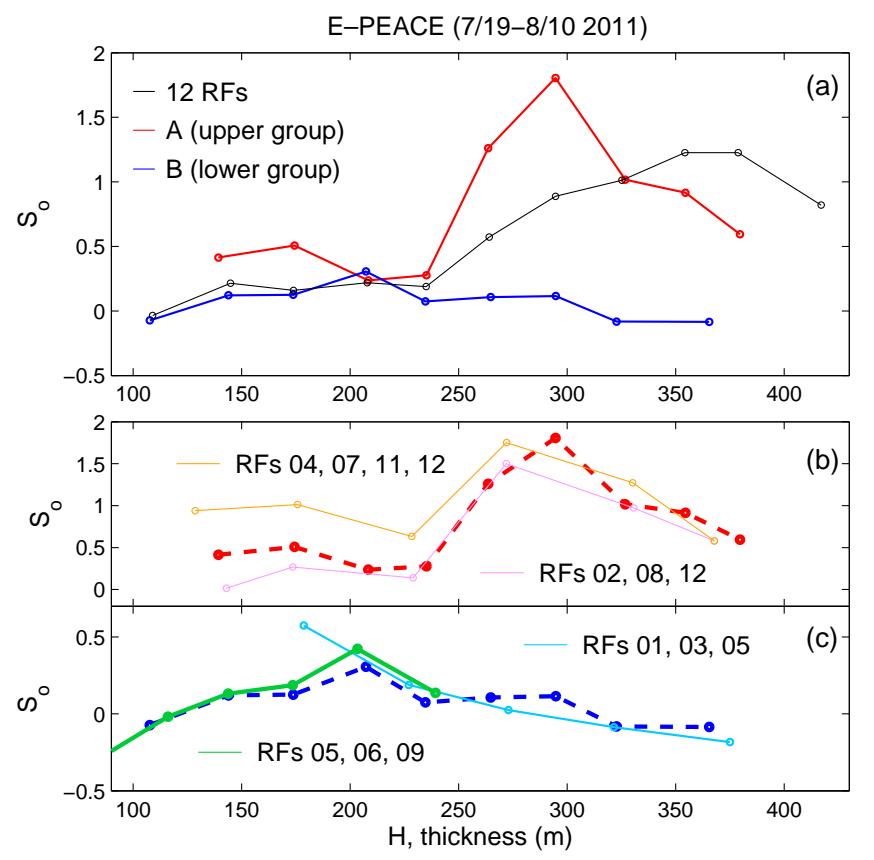

Figure 8. $S_{O}$ as a function of cloud thickness for (a) 12 E-PEACE flights, for groups A and B shown in Fig. 7. (b) $S_{O}$ calculated with randomly resampled RFs within (b) group A and (c) group B. RFs indicate research flights. Dates are indicated in $\mathrm{mm} / \mathrm{dd}$ format.

of the $H$ interval. However, if the $H$ interval is chosen across a cloud thickness range in which $S_{o}$ changes substantially, the pattern of $S_{o}$ can be changed, indicating that the finer $H$ interval provides a more accurate $S_{o}$ variation.

Second, we estimated $S_{o}$ by randomly resampling the flights of E-PEACE to see whether the sequential $1 \mathrm{~s}$ samples are statistically independent. $S_{o}$ calculated with random flights, at first glance, showed two distinctive types of behavior (not shown, but similar to Fig. 8a shown later). One is a similar pattern to that of the current $S_{o}$ shown in Fig. 4 while the other is an almost constant $S_{o}$ near zero. The cloud data sampled during E-PEACE formed two groups (denoted as A and B in Fig. 7). The $S_{o}$ pattern calculated with cloud data of group A is similar to $S_{o}$ shown in Fig. 4: $S_{o}$ is constant at lower $H$, followed by an increase then decrease (Fig. 8a). In contrast, $S_{o}$ values calculated from group B were relatively constant near zero (blue in Fig. 8a) or $S_{o}$ with the descending branch only (e.g., light blue in Fig. 8c). Further analysis revealed that the two RFs (RF13 and RF03) that have relatively small $N_{\mathrm{d}}$ with high $R$ explain the differences in the $S_{o}$ patterns (Fig. 9). If $S_{o}$ is calculated with cloud data that do not include data from clean with heavy precipitating environments (i.e., RF13 and RF03), $S_{o}$ shows a similar pattern as that in Fig. 4.
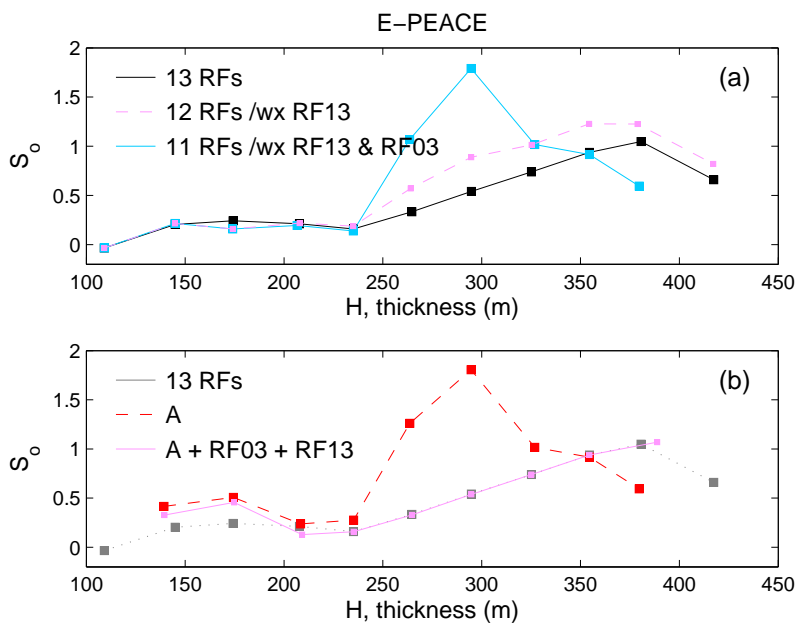

Figure 9. The effects of high precipitation (RF03 and RF13) on $S_{O}$ estimates. (a) $S_{o}$ calculated for 13 flights during E-PEACE in addition to when either, or both, RF03 and RF13 are excluded. RF03 and RF13 are the flights of high precipitation rates. (b) $S_{O}$ is calculated from group A with and without RF03 and RF13. $R$ and $N_{\mathrm{d}}$ information for each flight is shown in Fig. 7.

\subsection{The effect of autoconversion and accretion processes on $S_{o}$}

For cloud droplets to become raindrops (typical diameters of cloud droplets and drizzle drops are about 20 and $200 \mu \mathrm{m}$, respectively; Rogers and Yau, 1989), they have to increase in size significantly by the collision-coalescence process (autoconversion and accretion) Here, autoconversion primarily refers to faster-falling large cloud droplets that collect smaller cloud droplets in their paths as they fall through a cloud and grow larger; accretion refers to precipitation embryos that collect cloud droplets. In the intermediate LWP regime where $S_{o}$ increases with LWP or $H$ (ascending branch of $S_{o}$ ) the autoconversion process dominates. On the other hand, in the high LWP regime where $S_{o}$ decreases with LWP or $H$ (descending branch of $S_{o}$ ) the accretion process dominates (Feingold and Siebert, 2009; Feingold et al., 2013). The transition from the dominance of autoconversion to accretion is reported to occur when $D_{\mathrm{e}}$ exceeds $\sim 28 \mu \mathrm{m}$, and has been used as a rain initiation threshold in Sc (e.g., Rosenfeld et al., 2012). Jung et al. (2015) also showed that the precipitation embryos appeared (and initiated warm rain) when the mean droplet diameters were slightly less than $30 \mu \mathrm{m}$ from the salt seeding experiments during E-PEACE, in the NEP Sc decks (e.g., see Table 3, Figs. 6a and 7 in their study). Figure 10a shows that clouds during VOCALS consisted of numerous small droplets $(D<15 \mu \mathrm{m}$ in Fig. 10a), which primarily are involved with the autoconversion process except for one flight ( $D \sim 37 \mu \mathrm{m}, \mathrm{RF} 09,1$ November). The dominance of smaller droplets during VOCALS TO flights agree with the dominance of the ascending branch of $S_{o}$ in Fig. $4 \mathrm{~b}$. 
On the other hand, E-PEACE Sc clouds are composed of larger-sized droplets as well as small droplets (Fig. 10b).

\section{Discussion}

This study shows the consistent behavior of $S_{o}$ as a function of a key macrophysical cloud property regardless of cloud type; i.e., $S_{o}$ increases with increasing $H$ (ascending branch) and peaks at intermediate $H$ before $S_{o}$ decreases with $H$ (descending branch) in both $\mathrm{Sc}$ and $\mathrm{Cu}$ (Fig. 4). The results from marine cumulus clouds (BACEX and KWACEX) are consistent with previous modeling and observational studies of warm cumulus clouds (Sorooshian et al., 2009, 2010; Jiang et al., 2010; Duong et al., 2011; Feingold and Siebert, 2009; Feingold et al., 2013). However, $S_{o}$ values estimated from marine stratocumulus clouds (E-PEACE and VOCALS) are inconsistent with previous in situ observations of warm stratocumulus clouds (Terai et al., 2012; Mann et al., 2014), but are consistent with previous satellite observations of weakly precipitating Sc (Sorooshian et al., 2010), global climate model simulations (Gettelman et al., 2013; Hill et al., 2015), and box and parcel model studies (Feingold et al., 2013) of Sc.

Possible reasons for why the current results differ from those in previous studies of Sc are discussed here mainly by comparing results to those from the Terai et al. (2012) study. The inconsistent behaviors of $S_{o}$ between our study and theirs may be due to a number of factors. One of the most fundamental reasons could be in the differences in the cloud fields that were sampled. In the SEP Sc decks, drizzle intensity and frequency tend to increase westward from the coast (e.g., Bretherton et al., 2010) and their data set included several pockets of open cells (POCs) with strong precipitation (personal communication with $\mathrm{C}$. Terai). It should be noted that the VOCALS C-130 flights (Terai et al., 2012) sampled the cloud fields along $20^{\circ} \mathrm{S}$ (mainly over the open ocean), whereas the VOCALS TO flights sampled the Sc decks near the continents (Fig. 1). The westward increases in frequency and intensity of drizzle coincident with the westward decrease in aerosols and $N_{\mathrm{d}}$, and also with larger LWP over the open ocean (e.g., Zuidema et al., 2012), suggest that the discrepancy possibly is contributed to the different cloud microphysical process working on the cloud field (autoconversion vs. accretion processes). Indeed, Gettelman et al. (2013) showed that the accretion process dominated during VOCALS C-130 flights; the accretion to autoconversion ratio was above 1 for all LWP ranges during VOCALS observation (e.g., Fig. 5a in their studies). Therefore, the enhanced (major) accretion process appears as a descending branch of $S_{o}$ predominantly. Hill et al. (2015) also showed the monotonic decrease of $S_{o}$ with LWP in the case that the cloud data consist of exclusively larger particles (e.g., radius $>20 \mu \mathrm{m}$ ).

Second, the higher $R$ threshold that Terai et al. (2012) used could contribute to the discrepancies. Terai et al. (2012) used
$R=0.14 \mathrm{~mm} \mathrm{~d}^{-1}$ as a minimum $R$ threshold to estimate $S_{o}$, where $0.14 \mathrm{~mm} \mathrm{~d}^{-1}$ corresponds to $-15 \mathrm{dBz}$ from the $Z-R$ relationship that they used $\left(R=2.01 Z^{0.77}\right.$ from Comstock et al., 2004). This $R$ threshold is possibly too high to capture the autoconversion processes that occur in more lightly precipitating clouds such as clouds sampled during VOCALS TO flights. As a result, the high value of minimum $R$ threshold may primarily capture the accretion process, which may contribute to the descending branch of $S_{o}$ in their study. As an example, this $R$ threshold rejects all the data in Fig. 2a (VOCALS TO flights) except for 1 day (RF09, 1 November) when the mean effective diameter (at cloud base) is about $37 \mu \mathrm{m}$ (Fig. 10a) and the accretion process dominates for the day. Further, the impact of the $R$ threshold on the $S_{o}$ estimates is evident in Fig. B2. Figure B2 shows that $S_{o}$ decreases as the larger minimum $R$ threshold is used, in particular at larger $H$. Figure 9 also shows how clouds of low $N_{\mathrm{d}}$ with high $R$ (e.g., RF03 and RF13 of E-PEACE) alter the behavior of $S_{o}$. The choice of minimum $R$ threshold can change the data set that will be used for the estimates of $S_{o}$. The $S_{o}$ metric is designed to show the impact of aerosols on precipitation; as aerosol increases, smaller sizes of numerous droplets form, and those droplets suppress the collisioncoalescence process, and in turn, precipitation. Therefore, to study the extent that aerosols suppress precipitation, it would be more appropriate to encompass the full range of weakly to heavily precipitating clouds that include both autoconversion and accretion processes. It is also noted that the framework of precipitation susceptibility is to measure the impact of aerosol perturbations on the precipitation suppression, and thus, the concept of $S_{o}$ may not adequately apply to the clouds that are already heavily precipitating since the accretion process has little dependence on $N_{\mathrm{d}}$. In addition to decreasing the LWP, the precipitation itself can scavenge aerosols, leading to lower $N_{\mathrm{d}}$.

Third, the overall high values shown in Terai et al. (2012) ( $S_{o}$ begins with around 3 near $H \sim 50 \mathrm{~m}$ and ends with $S_{o} \sim 0.8$ near $H \sim 500 \mathrm{~m}$ ) may reflect the effects of wet scavenging (Fig. 11a; see also Duong et al., 2011), especially by considering that their data set included several POCs with strong precipitation. We also noted that $S_{o}$ calculated from the 13 E-PEACE flights was about 0.62 . However, $S_{o}$ calculated from 12 E-PEACE flights that excluded one rainy day was about 0.42 , which is consistent with larger $S_{o}$ in the presence of (heavy) precipitation possibly due to the wet scavenging (but it is also possible the lower $S_{o}$ is due to the microphysical process). Consistently, $S_{o}$ values calculated from 9 BACEX flights $(\mathrm{Cu})$, which excluded 3 heavy precipitation cases, were also shifted to lower values than those estimated from the entire 13 flights (not shown).

Fourth, Terai et al. (2012) used column-maximum $Z$ and then converted the $Z$ to $R$ by using a $Z-R$ relationship for those time periods when the lidar could not determine the cloud-base height due to interference from heavy precipitation. This procedure can overestimate precipitation for a 

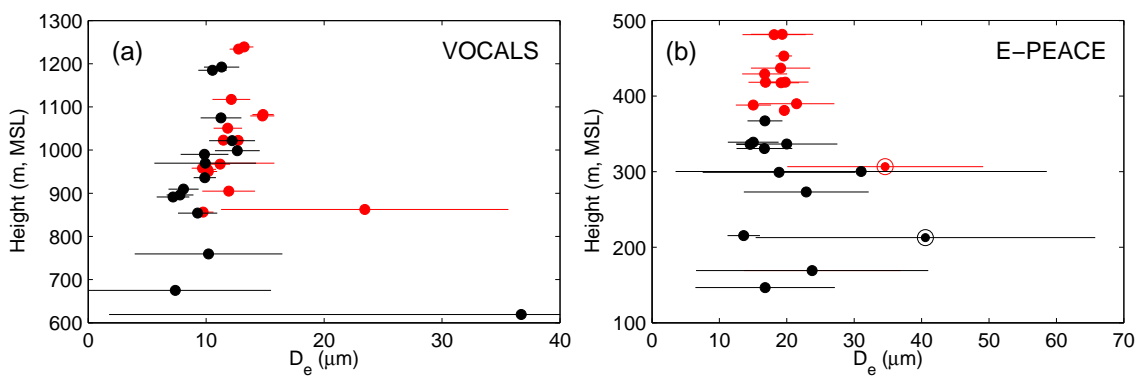

Figure 10. Distribution of effective diameters (mean $\pm 1 \sigma$ ) for (a) VOCALS TO flights and for (b) E-PEACE. Cloud droplets on 11 August are shown as double circles in (b). Black and red indicate cloud droplets sampled from cloud-base and mid-cloud heights, respectively.
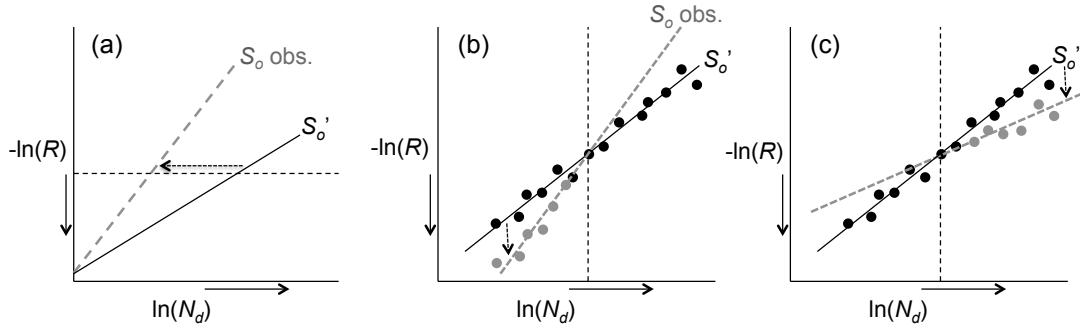

Figure 11. A visual description of (a) the effect of wet scavenging and (b-c) the impact of an increase in rainfall rate for a given range of $N_{\mathrm{d}}$ on the estimate of $S_{o}$. The solid line (with and without black filled circles) represents true (to be expected) $S_{o}$, whereas the dashed line (with and without gray filled circles) indicates observed (responded) $S_{o} . R$ increases downward on $y$ ordinate and $N_{\mathrm{d}}$ increase toward the right direction on $x$ abscissa. The direction of arrows inside the figure indicates the direction of $S_{o}$ changes.

given $N_{\mathrm{d}}$. If the procedure (i.e., overestimates of $R$ ) occurs in a low $N_{\mathrm{d}}$ regime (e.g., left half of the dotted line in Fig. 11b), the steeper slope (i.e., higher $S_{o}$ ) would be obtained (Fig. 11b). If the procedure happens in a high $N_{\mathrm{d}}$ regime, the lower slope would be attained (Fig. 11c). Based on Fig. 1 of their study, the former scenario (Fig. 11b) would occur, resulting in higher $S_{o}$ than expected.

Fifth, the $Z-R$ relationship that Terai et al. (2012) used ( $R=2.01 Z^{0.77}$, following Comstock et al. (2004)'s $Z=$ $25 R^{1.3}$ ) was derived for stratocumulus off of the coast of Peru, using a shipboard scanning C-band radar. The Sc sampled during the VOCALS C-130 flights may have a different microphysical process from which the original $Z-R$ relationship was derived. The microphysical processes are responsible for the formation of DSD, and the variability of DSD determines the theoretical limit of precipitation accuracy by radar via $Z-R$ relationship. That being said, changes in DSD imply different $Z-R$ relationships. The DSD variability (e.g., day to day, within a day, between physical processes and within a physical process) causes about 30-50\% of errors in $R$ estimates with a single $Z-R$ relationship (e.g., see Lee and Zawadzki, 2005, and references therein). Besides, the Comstock et al. (2004) $Z-R$ relationship was derived from drop sizes ranging from 2 to $800 \mu \mathrm{m}$ in diameter (for drops larger than $800 \mu \mathrm{m}$, extrapolation was used). The Sc from VOCALS C-130 flights included several POCs, while the clouds that the $Z-R$ relationship was derived from were characterized by persistent Sc, sometimes continuous and other times broken with intermittent drizzle throughout. Therefore, using the $Z-R$ relationship of Comstock et al. (2004) may result in some additional uncertainties in $R$ estimates in Terai et al. (2012) as the error of the $Z-R$ relationship becomes larger in the bigger drop sizes $(Z$ and $R$ are proportional to $\sim D^{6}$ and $\sim D^{4}$, respectively). Further, applying a $Z-R$ relationship to $\mathrm{W}$-band $(3 \mathrm{~mm})$ radar returns is not valid if there are any droplets greater than $1 \mathrm{~mm}$ since non-Rayleigh scattering (Mie effects) can dominate the radar reflectivity. Note that the Terai et al. (2012) $R$ retrievals were made with a W-band radar. However, it is also true that the in situ sampling of rain used in this study may miss a lot of raindrops because of the small sample volume of the probe. The errors in $R$ estimates with a single $Z-R$ relationship or $R$ measured from probes, however, may not critically affect the differences in $S_{o}$ between studies as the $S_{o}$ metric is less sensitive to data uncertainty by using the logarithmic form of the data (Eq. 1).

Lastly, Terai estimated $N_{\mathrm{d}}$ from the sub-cloud aerosols using an empirical relationship, which may also contribute to the differences. According to Jung (2012 in Fig. 4.5), the sub-cloud aerosols well represent the cloud-base $N_{\mathrm{d}}$ in the updraft regime, although these results are shown for the marine shallow cumulus clouds. Similarly, using the aerosol proxy from the satellite data for the $S_{o}$ calculation also needs caution. Jung et al. (2016) showed that aerosol op- 
tical depth (AOD) is not always a good indicator of the sub-cloud layer aerosols especially when the fine particles from long-distance continental pollution plumes reside above the boundary layer (e.g., Figs. 4-5 their study). Mann et al. (2014) used a sub-cloud $10 \mathrm{~m} \mathrm{CCN} \mathrm{(at} 0.55 \%$ supersaturation) for the $S_{o}$ calculation and showed a decreasing trend of $S_{o}$ with LWP as Terai et al. (2012) but their overall $S_{o}$ was smaller than those estimated from other field studies. In cases where sub-cloud aerosols are used for the $S_{o}$ estimates, these estimates give a smaller $S_{o}$ than those using $N_{\mathrm{d}}$ due to the decreasing fraction of aerosol activated with $N_{a}$ increasing, all else being equal (e.g., Lu et al., 2009).

\section{Conclusions}

The suppression of precipitation due to the enhanced aerosol concentrations $\left(N_{\mathrm{a}}\right)$ is a general feature of warm clouds. In this study, we examined precipitation susceptibility $S_{o}$ in marine low clouds by using in situ data obtained from four field campaigns with similar data sets; two of them focused on marine stratocumulus $(\mathrm{Sc})$, and two targeted shallow cumulus $(\mathrm{Cu})$ clouds. We estimate $S_{o}$ with 1 s data, with data averaged over an $e$-folding timescale, and data subsampled randomly from flights, with the key results preserved regardless of the method used. This study is the first to show with airborne data that for both $\mathrm{Sc}$ and $\mathrm{Cu}, S_{o}$ increases with increasing cloud thickness $H$, and peaks at an intermediate $H$ before decreasing. For example, $R$ is most susceptible for clouds of medium-deep depth, such as $H \sim 380 \mathrm{~m}$ for Sc in NEP where $H$ varies between 100 and $450 \mathrm{~m}$, and $H \sim 1200$ $1400 \mathrm{~m}$ for $\mathrm{Cu}$ in the Caribbean Sea where $H$ ranges from 200 to $1600 \mathrm{~m}$. On the other hand, $R$ is less susceptible to $N_{\mathrm{d}}$ in both shallow non-precipitating and deep heavily precipitating cloud regimes for both $\mathrm{Sc}$ and $\mathrm{Cu}$. The results are consistent with previous studies of warm cumulus clouds, but inconsistent with those of warm marine stratocumulus clouds in situ observations.

We suggest several possible reasons for why these results differ from those in previous studies of Sc, for example, by comparing with in situ measurements of Terai et al. (2012). The sources of these uncertainties include the following: (i) geographical location of cloud decks that may be related to the predominant cloud microphysical process at work (e.g., accretion process), (ii) $R$ threshold differences, (iii) wet scavenging effects (causing high values of $S_{o}$ ), (iv) the use of maximum column $Z$ to convert $R$ under heavy rain conditions where cloud base is not defined, (v) the use of the $Z-R$ relationship to estimate $R$, and (vi) the use of sub-cloud aerosols to estimate cloud-base $N_{\mathrm{d}}$.

We also found that the details of $N_{\mathrm{d}}$ (e.g., Fig. B1) or how the cloud base is determined (Fig. 4) have little effect on both $S_{o}$ values and the qualitative $H$-dependent behavior. Further, here we emphasize and caution that the choice of the $R$ threshold for the data analysis is important because the chosen threshold possibly can alter the character of the data set used to calculate $S_{o}$ by subsampling the data. For example, if a high value of the minimum $R$ threshold is chosen in a data set where the majority of data have low precipitation (e.g., VOCALS TO flights, Fig. 2a) and/or in the bimodal population of precipitation, the threshold would, by chance, eliminate/reduce the influence of the autoconversion process in favor of the accretion process. Further, Fig. B2 shows that the $S_{o}$ decreases as the minimum $R$ threshold increases. This study shows that the VOCALS C-130 flight data sets are likely dominated by the accretion process occurring naturally (geographically remote ocean areas where POCs are often observed) and by the choice of high $R$ thresholds.

The values of $S_{o}$ in this study were calculated from in situ measurements, and thus, no issues associated with the retrieval (e.g., satellite data), empirical relationships (e.g., $Z-$ $R$ relationship), or assumptions (e.g., relations between subcloud aerosols and cloud-base $N_{\mathrm{d}}$ ) are encountered for the calculation of $S_{o}$. A drawback, however, is the much smaller sampling volume of the in situ microphysical probes compared to a radar volume, as this may generate an underestimate of the rain rate. Further, we calculated $S_{o}$ separately for $\mathrm{Cu}$ and $\mathrm{Sc}$ to avoid any possible issues that may arise from combining different cloud types (Sect. 2.4). The results, however, should be used with caution when comparing to other studies in quantifying $S_{o}$ as the dominating cloud process and the choices applied to calculate the parameters in $S_{o}$ estimates (Eq. 1) can differ widely.

The results of this work motivate future studies examining the same relationships with a more direct measurement of cloud depth using a cloud radar and/or LWP using a microwave radiometer, in addition to the instruments/sensors that measure/retrieve $R$ and $N_{\mathrm{d}}\left(N_{\mathrm{a}}\right.$ is also desirable). For the flight strategy, in-cloud level legs at multiple altitudes (cloud base, mid-cloud, and cloud top) with one sub-cloud level leg would be ideal to calculate $S_{o}$ and compare with other studies where $S_{o}$ is calculated with cloud base or vertically integrated variables. Level legs near the ocean surface and sounding(s) to examine the background thermodynamic structures on a given day are also recommended.

\section{Data availability}

The Twin Otter research aircraft data set is available from upon request by email at balbrecht@rsmas.miami.edu or ejung@rsmas.miami.edu. 


\section{Appendix A: Data}

Table A1. Table of acronyms and symbols.

\begin{tabular}{ll}
\hline Acronym & Expression \\
\hline BACEX & Barbados Aerosol Cloud Experiment \\
CAS & cloud aerosol spectrometer \\
CIP & cloud imaging probe \\
Cu & (shallow marine) cumulus (cloud) \\
DSD & drop size distribution \\
E-PEACE & Eastern Pacific Emitted Aerosol Cloud Experiment \\
$H$ & cloud thickness \\
KWACEX & Key West Aerosol Cloud Experiment \\
LCL & lifting condensation level \\
LWC & liquid water content \\
LWP & liquid water path \\
$N_{\mathrm{d}}$ & cloud droplet number concentration \\
PCASP & passive cavity aerosol spectrometer probe \\
POCs & pockets of open cells \\
$R$ & rainfall (precipitation) rate \\
Sc & stratocumulus (clouds) \\
$S_{O}$ & precipitation susceptibility \\
TO & Twin Otter \\
VOCALS-REx & VAMOS Ocean-Cloud-Atmosphere-Land Study Regional Experiment \\
$Z$ & radar reflectivity \\
\hline
\end{tabular}




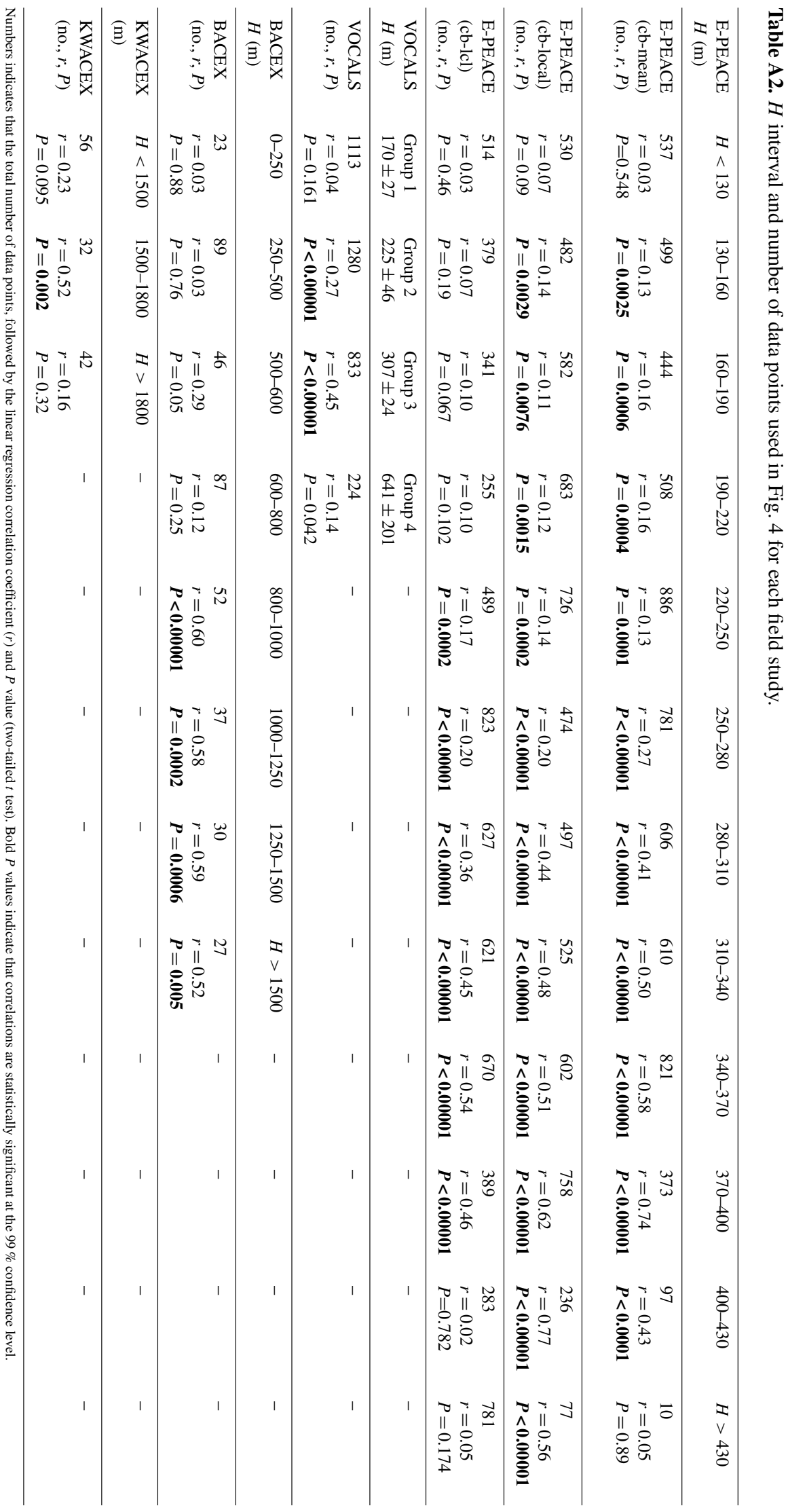


Appendix B: Sensitivity of $R$ and $N_{\mathrm{d}}$ thresholds to $S_{o}$ estimates

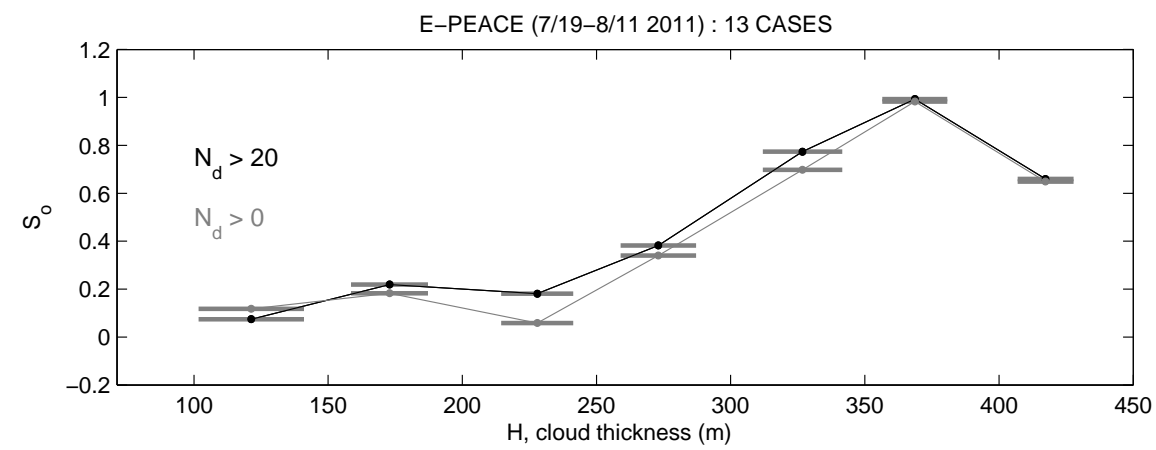

Figure B1. The sensitivity of $S_{o}$ to $N_{\mathrm{d}}$ threshold values. One standard deviation of mean thickness for given $H$ intervals is shown as horizontal bars. Dates are indicated in $\mathrm{mm} / \mathrm{dd}$ format.

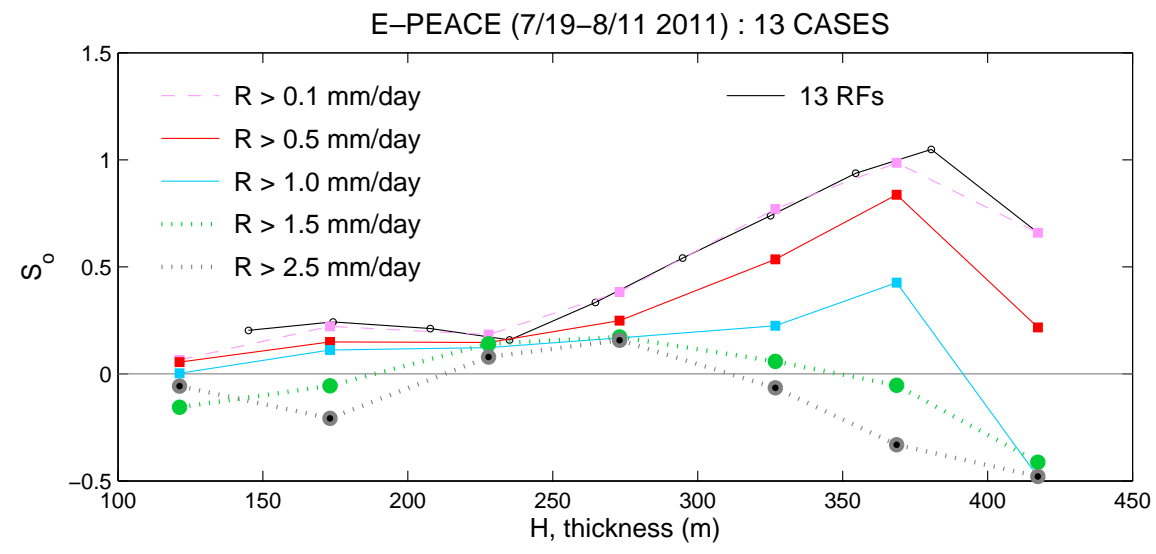

Figure B2. $H$-dependent precipitation susceptibility as a function of $R$ threshold values. Dates are indicated in $\mathrm{mm} / \mathrm{dd}$ format. 


\section{Appendix C: The effect of $H$ intervals on $S_{o}$ estimates}

$S_{o}$ calculated with different $H$ intervals can be seen by comparing Figs. 4 and A1 as an example. $H$ intervals in Fig. $4 \mathrm{~b}$ are about $30 \mathrm{~m}$, while $H$ intervals in Fig. A1 are about $50 \mathrm{~m}$. The qualitative $H$-dependent behavior of $S_{o}$ is robust regardless of the chosen $H$ intervals in case $1 \mathrm{~s}$ data are used. However, the chosen $H$ interval may have effect on the estimate of $S_{o}$ that is calculated with a fewer data points, such as $S_{o}$ that is calculated with data averaged over the $e$-folding time.

The effect of $H$ intervals on $S_{o}$ estimates, which is estimated with data averaged over the $e$-folding time, is shown in Fig. B1. In summary, the results are robust regardless of $H$ interval in general. However, if the $H$ interval is chosen across the cloud thickness where the $S_{o}$ changes substantially (such as in which the cloud properties change substantially), the pattern of $S_{o}$ can be changed, indicating that the finer $H$ interval would provide more accurate $S_{o}$. This is shown in Figs. 7 and 8. In Fig. 7, an $H$ interval of $50 \mathrm{~m}$ hides the variation of $S_{o}$ between $H 150$ and $200 \mathrm{~m}$. The $\ln \left(N_{\mathrm{d}}\right)$ and $-\ln (R)$ diagrams for $H$ widths of 40 and $50 \mathrm{~m}$ are shown in Fig. 7. However, in case that the $S_{o}$ does not change substantially across the $H$ intervals, the $S_{o}$ does not change even if the larger $H$ interval is used (e.g., Fig. 8d). For example, $S_{o}$ calculated with subsets of data (e.g., $220 \leq H<250 \mathrm{~m}$, $250 \leq H<280 \mathrm{~m}, 280 \leq H<310 \mathrm{~m})$ are $\sim 0.24-0.25$. If the $S_{o}$ is estimated with all the data that fall into the three intervals (e.g., $H>200 \mathrm{~m}$ ), the value is about 0.28 , which is similar to three individual $S_{o}$ values. The results may indicate that the cloud properties, such as cloud thickness where the cloud begins to precipitate, could be of importance for accurate estimates of $S_{o}$ by affecting the optimal $H$ interval and/or ranges.

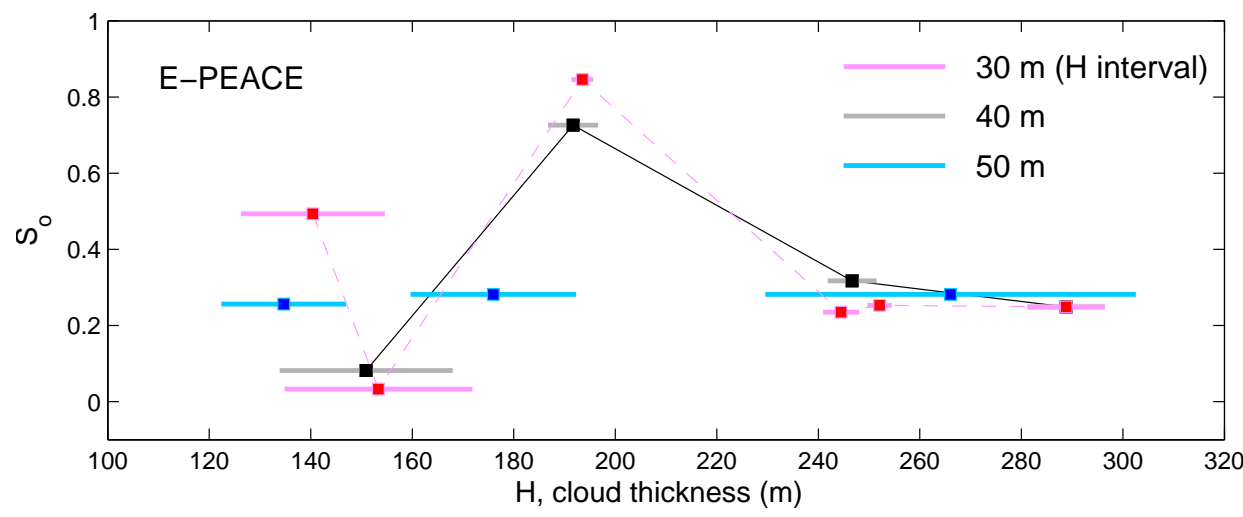

Figure C1. $S_{O}$ is calculated with cloud data that are averaged over an $e$-folding time for E-PEACE. $S_{o}$ calculated with three $H$ intervals $(\Delta 30 \mathrm{~m}, \Delta 40 \mathrm{~m}$, and $\Delta 50 \mathrm{~m})$ is shown. Horizontal bar indicates $\pm 1 \sigma$ cloud thickness for a given $H$ interval. 
E-PEACE, $\mathrm{H}$ interval $=40 \mathrm{~m}$

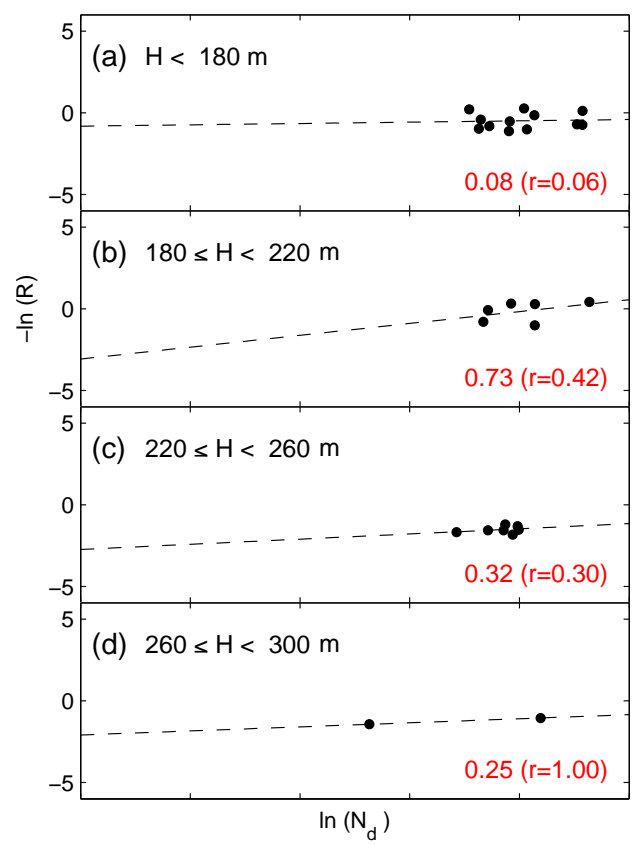

E-PEACE, $\mathrm{H}$ interval $=50 \mathrm{~m}$

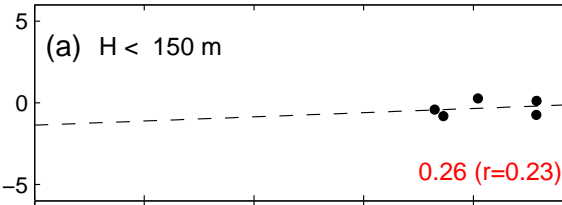

(b) $150 \leq \mathrm{H}<200 \mathrm{~m}$

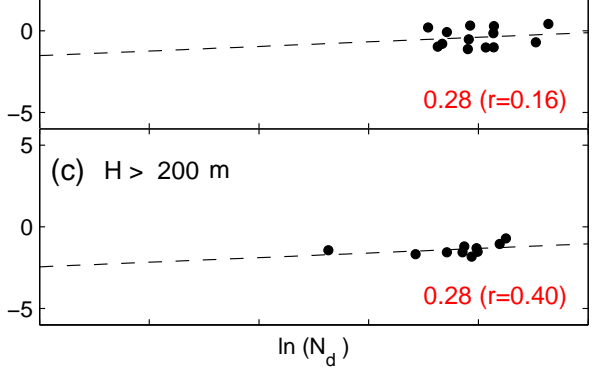

(c) $\mathrm{H}>200 \mathrm{~m}$

Figure C2. The $\ln \left(N_{\mathrm{d}}\right)$ and $-\ln (R)$ diagrams with fixed $H$ intervals: (left) $\Delta H=40 \mathrm{~m}$, (right) $\Delta H=50 \mathrm{~m}$.

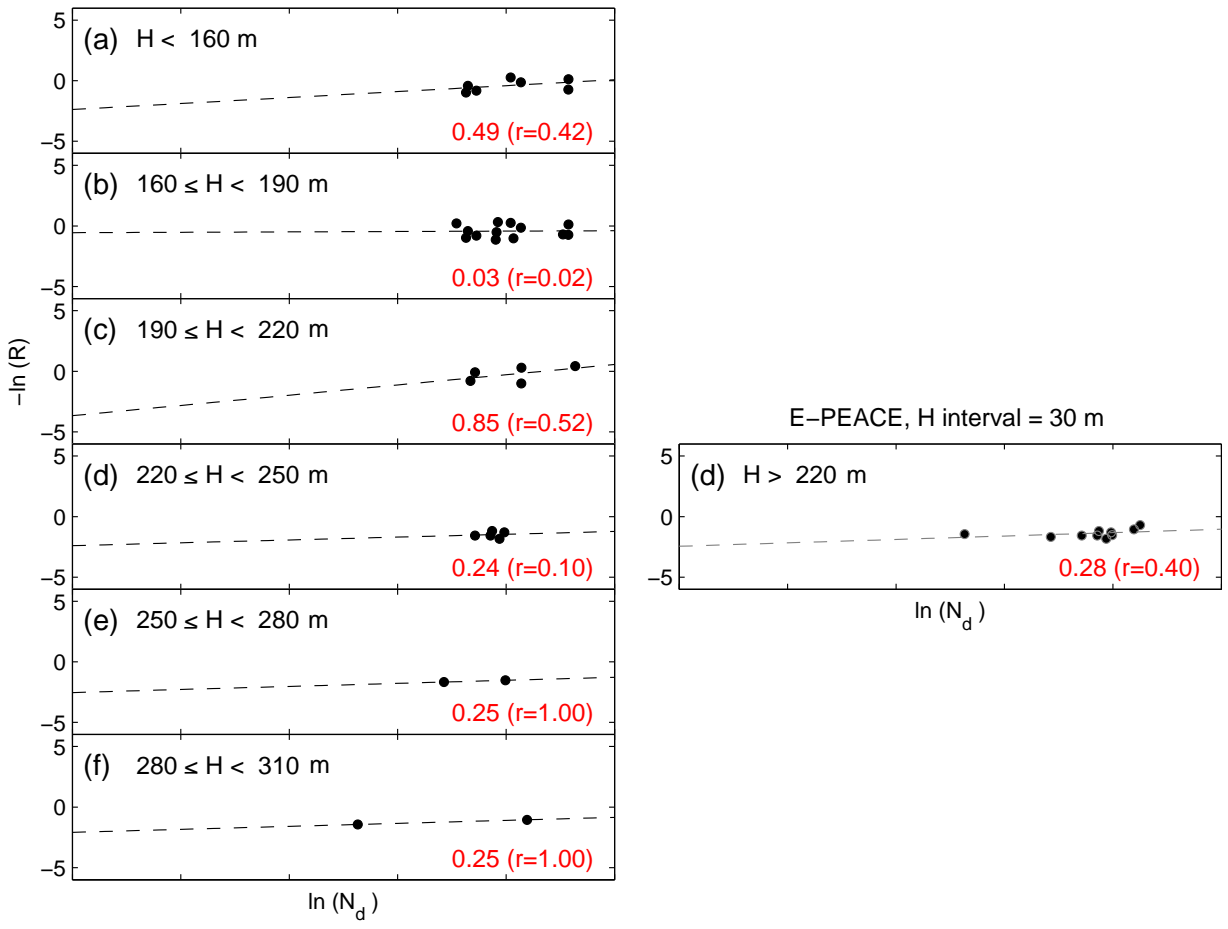

Figure C3. The $\ln \left(N_{\mathrm{d}}\right)$ and $-\ln (R)$ diagrams with fixed $H$ intervals $(\Delta H=30 \mathrm{~m})$. 
Acknowledgements. The authors gratefully acknowledge the crews of the CIRPAS Twin Otter for their assistance during these field campaigns. EJ acknowledges Chris Terai for his helpful discussion of the estimate of precipitation susceptibility. This study was funded by ONR grants N000140810465, N00014-10-1-0811, N00014-16-1-2567, and NSF grant AGS-1008848. We thank three anonymous reviewers for thoughtful suggestions and constructive criticism that have helped to improve the manuscript.

Edited by: H. Wang

Reviewed by: three anonymous referees

\section{References}

Bretherton, C. S., Wood, R., George, R. C., Leon, D., Allen, G., and Zheng, X.: Southeast Pacific stratocumulus clouds, precipitation and boundary layer structure sampled along $20^{\circ} \mathrm{S}$ during VOCALS-REx, Atmos. Chem. Phys., 10, 10639-10654, doi:10.5194/acp-10-10639-2010, 2010.

Comstock, K. K., Wood, R., Yuter, S. E., and Bretherton, C. S.: Reflectivity and rain rate in and below drizzling stratocumulus, Q. J. Roy. Meteor. Soc., 130, 2891-2918, 2004.

Duong, H. T., Sorooshian, A., and Feingold, G.: Investigating potential biases in observed and modeled metrics of aerosol-cloudprecipitation interactions, Atmos. Chem. Phys., 11, 4027-4037, doi:10.5194/acp-11-4027-2011, 2011.

Feingold, G. and Siebert, H.: Clouds in the Perturbed Climate System: Their Relationship to Energy Balance, Atmospheric Dynamics, and Precipitation, edited by: Heintzenberg, J. and Charlson, R. J., Strüngmann, Forum Reports, 2, Cambridge, MA: The MIT Press, 597 pp., 2009.

Feingold, G., McComiskey, A., Rosenfeld, D., and Sorooshian, A.: On the relationship between cloud contact time and precipitation susceptibility to aerosol, J. Geophys. Res., 118, 10544-10554, 2013.

Gerber, H., Arends, B. G., and Ackerman, A. S.: A new microphysics sensor for aircraft use, Atmos. Res., 31, 235-252, 1994.

Gettelman, A., Morrison, H., Terai, C. R., and Wood, R.: Microphysical process rates and global aerosol-cloud interactions, Atmos. Chem. Phys., 13, 9855-9867, doi:10.5194/acp-13-98552013, 2013.

Hill, A. A., Shipway, B. J., and Boutle, I. A.: How sensitive are aerosol-precipitation interactions to the warm rain representation?, J. Adv. Model. Earth Syst., 7, 987-1004, doi:10.1002/2014MS000422, 2015.

Intergovernmental Panel on Climate Change (IPCC): The Physical Science Basis. Contribution of Working Group I to the Fifth Assessment Report of the Intergovernmental Panel on Climate Change, edited by: Stocker, T. F., Qin, D., Plattner, G.-K., Tignor, M., Allen, S. K., Boschung, J., Nauels, A., Xia, Y., Bex, V. and Midgley, P. M., Cambridge University Press, Cambridge, United Kingdom and New York, NY, USA, 2013.

Jiang, H., Feingold, G., and Sorooshian, A.: Effect of aerosol on the susceptibility and efficiency of precipitation in trade cumulus clouds, J. Atmos. Sci., 67, 3525-3540, 2010.

Jones, A., Roberts, D. L., Woodage, M. J., and Johnson, C. E.: Indirect sulphate aerosol forcing in a climate model with an in- teractive sulphur cycle, J. Geophys. Res., 106, 20293-20310, doi:10.1029/2000JD000089, 2001.

Jung, E.: Aerosol-Cloud-Precipitation Interactions in the Trade Wind Boundary Layer, $\mathrm{PhD}$ dissertation, 184 pp., available at: http://scholarlyrepository.miami.edu/oa_dissertations/900, 2012.

Jung, E., Albrecht, B. A., Prospero, J. M., Jonsson, H. H., and Kreidenweis, S. M.: Vertical structure of aerosols, temperature and moisture associated with an intense African dust event observed over the Eastern Caribbean, J. Geophys. Res., 118, 4623-4643, doi:10.1002/jgrd.50352, 2013.

Jung, E., Albrecht, B. A., Jonsson, H. H., Chen, Y.-C., Seinfeld, J. H., Sorooshian, A., Metcalf, A. R., Song, S., Fang, M., and Russell, L. M.: Precipitation effects of giant cloud condensation nuclei artificially introduced into stratocumulus clouds, Atmos. Chem. Phys., 15, 5645-5658, doi:10.5194/acp-15-56452015, 2015.

Jung, E., Albrecht, B. A., Feingold, G., Jonsson, H. H., Chuang, P., and Donaher, S. L.: Aerosols, clouds, and precipitation in the North Atlantic trades observed during the Barbados aerosol cloud experiment - Part 1: Distributions and variability, Atmos. Chem. Phys., 16, 8643-8666, doi:10.5194/acp-16-8643-2016, 2016.

Khairoutdinov, M. and Kogan, Y.: A new cloud physics parameterization in a large-eddy simulation model of marine stratocumulus, Mon. Weather Rev., 128, 229-243, 2000.

Lee, G. and I. Zawadzki, I.: Variability of drop size distributions: time-scale dependence of the variability and its effects on rain estimation, J. Appl. Meteor., 44, 241-255, doi:10.1175/JAM2183.1, 2005.

Leith, C. E.: The Standard Error of Time-Average Estimates of Climatic Means, J. Appl. Meteor., 12, 1066-1069, doi:10.1175/1520-0450(1973)012<1066:TSEOTA>2.0.CO;2, 1973.

Lu, M. -L., Sorooshian, A., Jonsson, H. H., Feingold, G., Flagan, R. C., and Seinfeld, J. H.: Marine stratocumulus aerosol-cloud relationships in the MASE-II experiment: Precipitation susceptibility in eastern Pacific marine stratocumulus, J. Geophys. Res., 114, D24203, doi:10.1029/2009JD012774, 2009.

Mann, J. A. L, Chiu, J. C., Hogan, R. J., O’Connor, E. J., L'Ecuyer, T. S., Stein, T. H. M., and Jefferson, A.: Aerosol impacts on drizzle properties in warm clouds from ARM Mobile Facility maritime and continental deployments, J. Geophys. Res., 119, 41364148, doi:10.1002/2013JD021339, 2014.

Nuijens, L., Serikow, I., Hirsch, L., Lonitz, K., and Stevens, B.: The distribution and variability of low-level cloud in the NorthAtlantic trades, Q. J. Roy. Meteor. Soc., 140, 2364-2374, 2014.

Painemal, D. and Zuidema, P.: Assessment of MODIS cloud effective radius and optical thickness retrievals over the Southeast $\mathrm{Pa}$ cific with VOCALS-REx in situ measurements, J. Geophys. Res., 116, D24206, doi:10.1029/2011JD016155, 2011.

Pawlowska, H. and Brenguier, J. L.: An observational study of drizzle formation in stratocumulus clouds for general circulation model (GCM) parameterizations, J. Geophys. Res., 108, 8630, doi:10.1029/2002JD002679, 2003.

Rasch, P. J. and Kristjansson, J. E.: A comparison of the CCM3 model climate using diagnosed and predicted condensate parameterizations, J. Climate, 11, 1587-1614, 1998.

Rauber, R. M., Ochs III, H. T., Di Girolamo, L., Göke, S., Snodgrass, E., Stevens, B., Knight, C., Jensen, J. B., Lenschow, D. 
H., Rilling, R. A., Rogers, D. C., Stith, J. L., Albrecht, B. A., Zuidema, P., Blyth, A. M., Fairall, C. W., Brewer, W. A., Tucker, S., Lasher-Trapp, S. G., Mayol-Bracero, O. L., Vali, G., Geerts, B., Anderson, J. R., Baker, B. A., Lawson, R. P., Bandy, A. R., Thornton, D. C., Burnet, E., Brenguier, J-L., Gomes, L., Brown, P. R. A., Chuang, P., Cotton, W. R., Gerber, H., Heikes, B. G., Hudson, J. G., Kollias, P., Krueger, S. K., Nuijens, L., O’Sullivan, D. W., Siebesma, A. P., and Twohy, C. H.: Rain in shallow cumulus over the ocean, B. Am. Meteorol. Soc., 88, 1912-1928, 2007

Rogers, R. R. and Yau, M. K.: A Short Course in Cloud Physics, 3rd Edn., International Series in Natural Philosophy, 290 pp., 1989.

Rosenfeld, D., Wang, H., and Rasch, P. J.: The roles of cloud drop effective radius and LWP in determining rain properties in marine stratocumulus, Geophys. Res. Lett., 39, L13801, doi:10.1029/2012GL052028, 2012.

Rotstayn, L. D. and Liu, Y.: A smaller global estimate of the second indirect aerosol effect, Geophys. Res. Lett., 32, L05708, doi:10.1029/2004GL021922, 2005.

Russell, L. M., Sorooshian, A., Seinfeld, J. H., Albrecht, B. A., Nenes, A., Ahlm, L., Chen, Y.-C., Coggon, M., Craven, J. S., Flagan, R. C., Frossard, A. A., Jonsson, H., Jung, E., Lin, J. J., Metcalf, A. R., Modini, R., Muelmenstaedt, J., Roberts, G. C., Shingler, T., Song, S., Wang, Z., and Wonaschuetz, A.: Eastern Pacific Emitted Aerosol Cloud Experiment, B. Am. Meteorol. Soc., 94, 709-729, doi:10.1175/BAMS-D-12-00015.1, 2013.

Sorooshian, A., Feingold, G., Lebsock, M. D., Jiang, H., and Stephens, G.: On the precipitation susceptibility of clouds to aerosol perturbations, Geophys. Res. Lett., 36, L13803, doi:10.1029/2009GL038993, 2009.

Sorooshian, A., Feingold, G., Lebsock, M. D., Jiang, H., and Stephens, G.: Deconstructing the precipitation susceptibility construct: improving methodology for aerosolcloud-precipitation studies, J. Geophys. Res., 115, D17201, doi:10.1029/2009JD013426, 2010.

Sorooshian, A., Prabhakar, G., Jonsson, H., Woods, R., Flagan, R. C., and Seinfeld, J. H.: On the presence of giant particles downwind of ships in the marine boundary layer, Geophys. Res. Lett., 42, 2024-2030, doi:10.1002/2015GL063179, 2015.

Stevens, B. and Feingold, G.: Untangling aerosol effects on clouds and precipitation in a buffered system, Nature, 461, 607-613, 2009.

Takemura, T., Nozawa, T., Emori, S., Nakajima, T. Y., and Nakajima, T.: Simulation of climate response to aerosol direct and indirect effects with aerosol transport-radiation model, J. Geophys. Res., 110, D02202, doi:10.1029/2004JD005029, 2005.

Terai, C. R., Wood, R., Leon, D. C., and Zuidema, P.: Does precipitation susceptibility vary with increasing cloud thickness in marine stratocumulus?, Atmos. Chem. Phys., 12, 4567-4583, doi:10.5194/acp-12-4567-2012, 2012.
Terai, C. R., Wood, R., and Kubar, T. L.: Satellite estimates of precipitation susceptibility in low-level marine stratiform clouds, J. Geophys. Res., 120, 8878-8889, 2015.

vanZanten, M. C., Stevens, B., Vali, G., and Lenschow, D. H.: Observations of drizzle in nocturnal marine stratocumulus, J. Atmos. Sci., 62, 88-106, 2005.

Wang, M., Ghan, S., Liu, X., L'Ecuyer, T. S., Zhang, K., Morrison, H. M., Ovchinnikov, R. E., Marchand, R., Chand, D., Qian, Y., and Penner, J. E.: Constraining cloud lifetime effects of aerosols using A-Train Satellite observations, Geophys. Res. Lett., 39, L15709, doi:10.1029/2012GL052204, 2012.

Wang, Z., Sorooshian, A., Prabhakar, G., Coggon, M. M., and Jonsson, H. H.: Impact of emissions from shipping, land, and the ocean on stratocumulus cloud water elemental composition during the 2011 E-PEACE Field Campaign, Atmos. Environ., 89, $570-580$, doi10.1016/j.atmosenv.2014.01.020, 2014.

Wonaschütz, A., Coggon, M., Sorooshian, A., Modini, R., Frossard, A. A., Ahlm, L., Mülmenstädt, J., Roberts, G. C., Russell, L. M., Dey, S., Brechtel, F. J., and Seinfeld, J. H.: Hygroscopic properties of smoke-generated organic aerosol particles emitted in the marine atmosphere, Atmos. Chem. Phys., 13, 9819-9835, doi:10.5194/acp-13-9819-2013, 2013.

Wood, R., Kubar, T. L., and Hartmann, D. L.: Understanding the Importantce of Microphysics and Macrophysics for Warm Rain in Marine Low Clouds. Part II: Heuristic Models of Rain Formation, J. Atmos. Sci., 66, 2973-2990, doi:10.1175/2009JAS3072.1, 2009.

Wood, R., Mechoso, C. R., Bretherton, C. S., Weller, R. A., Huebert, B., Straneo, F., Albrecht, B. A., Coe, H., Allen, G., Vaughan, G., Daum, P., Fairall, C., Chand, D., Gallardo Klenner, L., Garreaud, R., Grados, C., Covert, D. S., Bates, T. S., Krejci, R., Russell, L. M., de Szoeke, S., Brewer, A., Yuter, S. E., Springston, S. R., Chaigneau, A., Toniazzo, T., Minnis, P., Palikonda, R., Abel, S. J., Brown, W. O. J., Williams, S., Fochesatto, J., Brioude, J., and Bower, K. N.: The VAMOS Ocean-Cloud-AtmosphereLand Study Regional Experiment (VOCALS-REx): goals, platforms, and field operations, Atmos. Chem. Phys., 11, 627-654, doi:10.5194/acp-11-627-2011, 2011.

Zheng, X., Albrecht, B., Jonsson, H. H., Khelif, D., Feingold, G., Minnis, P., Ayers, K., Chuang, P., Donaher, S., Rossiter, D., Ghate, V., Ruiz-Plancarte, J., and Sun-Mack, S.: Observations of the boundary layer, cloud, and aerosol variability in the southeast Pacific near-coastal marine stratocumulus during VOCALSREx, Atmos. Chem. Phys., 11, 9943-9959, doi:10.5194/acp-119943-2011, 2011.

Zuidema, P., Leon, D., Pazmany, A., and Cadeddu, M.: Aircraft millimeter-wave passive sensing of cloud liquid water and water vapor during VOCALS-REx, Atmos. Chem. Phys., 12, 355-369, doi:10.5194/acp-12-355-2012, 2012. 